\title{
Advanced Tests for Skin and Respiratory Sensitization Assessment
}

Summary Report on the Sens-it-iv End Congress in Brussels, November 23-25, 2011

Costanza Rovida ${ }^{1}$, Stefan F. Martin ${ }^{2}$, Manon Vivier ${ }^{3}$, Hans Ulrich Weltzien ${ }^{4}$, and Erwin Roggen ${ }^{5}$

${ }^{1}$ Center for Alternatives to Animal Testing (CAAT)-Europe, University of Konstanz, Germany; ${ }^{2}$ Allergy Research Group, Department of Dermatology, University Medical Center Freiburg, Freiburg, Germany; ${ }^{3}$ Vrije Universiteit Brussel (VUB), Department of Toxicology, Dermato-Cosmetology and Pharmacognosy, Belgium; ${ }^{4}$ Max Planck Institute for Immunobiology and Epigenetics, Freiburg, Germany; ${ }^{5}$ Novozymes AS, Bagsvaerd, Denmark

\section{Summary}

Sens-it-iv is an FP6 Integrated Project that finished in March 2011 after 66 months of activity, thanks to 12 million $€$ of funding. The ultimate goal of the Sens-it-iv project was the development of a set of in vitro methods for the assessment of the skin and respiratory sensitization potential of chemicals and proteins. The level of development was intended to be at the point to enter the pre-validation phase. At the end of the project it can be concluded that the goal has been largely accomplished. Several advanced methods were evaluated extensively, and for some of them a detailed Standard Operating Procedure (SOP) was established. Other, less advanced methods also contributed to our understanding of the mechanisms driving sensitization.

The present contribution, which has been prepared with the support of CAAT-Europe, represents a short summary of what was discussed during the 3-day end congress of the Sens-it-iv project in Brussels. It presents a list of methods that are ready for skin sensitization hazard assessment. Potency evaluation and the possibility of distinguishing skin from respiratory sensitizers are also well advanced.

Keywords: skin sensitization, respiratory sensitization, in vitro methods, Integrated Testing Strategy, $3 D$ cultures

\section{Introduction}

The Sens-it-iv project was an FP6 Integrated Project funded with 12 million $€$ by the European Commission for the development of an in vitro strategy for the assessment of both skin and respiratory sensitization by chemicals and proteins. Sensit-iv is the acronym for Novel Testing Strategies for In vitro Assessment of Allergens. Private funding increased the total budget of the project to 20 million $€$. The project started on October 1 , 2005 and ended more than 5 years later, on March 31, 2011. The outline of the project is available on the official website (http://www.sens-it-iv.eu), while the general management was described by Rovida et al. (2007).

The Sens-it-iv consortium involved 28 research groups overall, of which 8 were from industry (including 3 SMEs), and 16 were from universities or other research institutes. The coordination was charged to Erwin Roggen of Novozymes A/S,
Denmark, aided by the vice-coordinator Hans-Ulrich Weltzien from the Max-Planck Institute for Immunobiology and Epigenetics, Freiburg Germany.

The ultimate goal of the Sens-it-iv project was the development of a set of in vitro methods for the assessment of the skin and respiratory sensitization potential of chemicals and proteins. The level of development was intended to be at the point to enter the pre-validation phase. After 66 months of work, it could be concluded that the goal was largely accomplished. Several advanced methods were evaluated extensively, and for some of them a detailed standard operating procedure (SOP) was established for pre-validation purposes. Other, less advanced methods contributed to our understanding of the mechanisms driving sensitization as well.

Several opportunities were employed to assure dissemination of results. During the course of the project, 44 newsletters were released, presenting the main achievements of the project. Fly- 
ers for the lay public, plus presentations at scientific congresses, and more than 110 publications in high ranking journals for the scientific community were used intensively. In addition, more innovative strategies were put in place during the final years of the project. The University of Utrecht organized hands-on summer courses for teaching the application of the newly developed assays. Another strategy was to provide e-learning protocols for the most advanced assays, which remain accessible via the Sens-it-iv website (http://www.sensitive-learning.eu, accessed on August 1, 2012).

Since its founding in 2010 (Daneshian et al., 2010), CAATEurope has been interested in all European projects that focus on the development of new strategies for toxicity testing in the interest of the 3Rs, and in the promotion of the vision depicted in the Tox21c document (NRC, 2007), which seeks a toxicology that is based on the mechanisms of action in humans rather than on animal models whose relevance is questionable. For this reason, CAAT-Europe accepted the role as co-partner in the organization of a final event that had the goal of presenting the achievements of the Sens-it-iv project in combination with the latest discoveries by other research teams that are active in the field of skin and respiratory sensitization.

The present contribution represents a short summary of what was discussed in a 3-day symposium that took place in Brussels on November 23-25, 2011. It was not the ambition of the authors to extensively cover all the topics or to provide a review on this theme. This manuscript intends to reflect the discussions that were triggered by the presentations. Each section contains useful references for those who want to go into more detail. It is also advised to visit the Sens-it-iv website and the collection of newsletters that can be found at http://www.sens-it-iv.eu/content/newsletter.php (accessed on February 18, 2012).

\section{Mechanistic basis and clinical problems of sensitization}

Chair: S. F. Martin

In recent years, our understanding of the mechanisms driving sensitization and allergy has improved considerably. However, during this meeting only two aspects were presented in detail: i) sensitization via the respiratory tract, and ii) the role of T-cells in the determination of the clinical reaction.

Several types of chemical allergens can be distinguished:

1. Haptens, i.e., chemically reactive chemicals that bind covalently to proteins and eventually are recognized as hapten modified peptides;

2. Pro/pre-haptens, i.e., chemicals that do not bind spontaneously to proteins or peptides but need to be either metabolized or modified by atmospheric agents;

3. Small molecules and metal ions such as nickel, which form non-covalent high affinity complexes with proteins and peptides and are recognized as MHC/peptide/hapten complexes by T-cells.

Respiratory sensitization is considered in GHS (Globally Harmonized System, http://www.osha.gov/dsg/hazcom/ghs.html, accessed on August 1, 2012) as a toxic effect of main concern, together with Carcinogenicity, Mutagenicity, and Reproductive Toxicity (CMR).

Sensitization of the respiratory tract: toxicology issues and challenges (by Ian Kimber)

Occupational asthma provokes many problems, with about 1000 new cases per year in the UK alone. The symptoms may derive from a non-specific irritation of the respiratory tract, but $90 \%$ of the cases derive from an immunological reaction following exposure to very low allergen concentrations. The clinical picture is varied and not always immediately recognizable. After a latency period of several months, typical symptoms appear gradually with wheezing, chest tightness, coughing, breathlessness, sneezing, and blocked or runny nose. In both cases, improvement usually comes immediately after removal of exposure.

Most of the allergens are proteins, including environmental allergens (e.g., pollen, house dust, mites), processed foods (e.g., ovalbumin) and some industrial proteolytic enzymes (e.g., alcalase). In addition, low molecular weight (MW) chemicals also may cause respiratory allergy in humans. The number of confirmed chemical respiratory allergens probably numbers no more than 70, including diisocyanates, anhydrides, certain platinum salts, and some reactive dyes.

It has frequently been assumed incorrectly that sensitization of the respiratory tract to chemicals is caused exclusively by inhalation exposure to the allergen. There is increasing evidence that, in fact, skin exposure to chemical respiratory allergens also can provoke the quality of immune response that is necessary for sensitization of the respiratory tract. This has important implications for risk assessment and risk management. In the case of protein respiratory allergens, inhalation is probably the most common route through which sensitization is acquired (Kimber et al., 2007)

It is well established that protein respiratory allergy is dependent upon IgE antibody. For most common chemical respiratory allergens there are confirmed cases where sensitization is associated with a specific IgE antibody. However, it is clear that symptomatic patients do not always have detectable serum $\operatorname{IgE}$ antibody; this has been the experience with diisocyanates in particular. It is possible, for a variety of technical reasons, that the degree of association between $\operatorname{IgE}$ antibody and chemical respiratory allergy has been underestimated. Nevertheless it has to be acknowledged that there may be IgE-antibody-independent mechanisms through which sensitization of the respiratory tract to chemicals can be acquired. Although there may be some uncertainty regarding a universal mandatory role for IgE antibody in the development of respiratory sensitization to chemical allergens, there is good reason to suppose that there is a strong association with T helper (Th) type 2 immune responses (Kimber et al., 2007)

A variety of methods have been proposed for the identification and characterization of chemical respiratory allergens. These include guinea pig inhalation models, or animal models in which sensitization is induced by dermal exposure, and where activity is measured as a function of inhalation challenge-induced res- 
piratory reactions. In addition, a mouse IgE test and cytokine fingerprinting have been developed, and the latter has been of some utility. However, it is important to emphasize that, currently, there are no validated or widely recognized methods (animal or non-animal) for the identification of chemical respiratory allergens. Perhaps one of the main reasons why it has proven so difficult to develop methods that are universally acceptable is that some uncertainty remains about the immunological mechanisms that result in the acquisition of respiratory sensitization, and in particular the requirement for IgE antibody.

In vitro and in silico approaches inspire hope, but a lot of work and research has to be invested before coming to a conclusion.

\section{Mechanistic and clinical aspects of skin sensitization (by Jean-Francois Nicolas)}

Allergic contact dermatitis (ACD), also referred to as contact hypersensitivity, is one of the most common occupational diseases. It is caused by repeated skin exposure to contact allergens called haptens. Proteins usually are excluded, as they are not absorbed by the skin. However, in patients with skin barrier defects, such as in atopic dermatitis, proteins may penetrate the epidermis and induce eczema. The clinical appearance of eczema and dermatitis often are used synonymously to denote a polymorphic pattern of inflammation of the skin characterized, at least in its acute phase, by erythema, vesiculation, and pruritus (Krasteva et al., 1999).

Because ACD is mediated by T-cells, an in-depth understanding of the processes underlying T-cell stimulation and differentiation is essential to predicting the antigenicity and toxicological characteristic of a substance and to develop suitable tests.

$\mathrm{ACD}$, also referred to as contact hypersensitivity (CHS) and studied extensively in the mouse CHS model, is mediated by $\mathrm{CD}^{+}$T-cells, which are primed in lymphoid organs during the sensitization phase and are recruited to the skin upon re-exposure to the hapten (Fig. 1). Subsets of $\mathrm{CD}^{+}$ T-cells endowed with suppressive activity are responsible for both the down regulation of eczema in allergic patients and the prevention of priming to haptens in non-allergic individuals. Therefore, ACD should be considered a breakdown of the skin immune tolerance to haptens. Recent advances in the pathophysiology of ACD have demonstrated the important role of skin innate immunity in sensitization and have revisited the dogma that Langerhans cells are mandatory for $\mathrm{CD}^{+} \mathrm{T}$-cell priming. They also have introduced mast cells as a pivotal actor in the magnitude of the inflammatory reaction. Finally, the most recent studies address the nature, the mode, and the site of action of the regulatory T-cells that control the skin inflammation with the aim of developing new strategies of tolerance induction in allergic patients. Since T-cells are the pathogenic effector cells in chemical-induced ACD, respiratory allergies or ADR (Adverse Drug Reaction), T-cell based in vitro assays are considered very useful for identification of contact and respiratory allergens, as well as hazardous drugs. The role of B-cells is controversial, and therefore assays based on B-cell response have not yet been developed.

Research in the skin sensitization area is very active and is constantly fed with new data. The primary focus of the discussion was on delayed type hypersensitivity (DTH), which is the result of repeated contact of the skin with skin sensitizers (haptens). Haptens are very diverse, low molecular weight molecules that, as a mandatory feature, must modify self proteins to become immunogenic and to induce T-cell activation. In contrast to irritants that induce no specific immune response, haptenated peptides are recognized by T-cells, either through MHC class I or II, depending on the type of complex. The mechanistic details are reviewed elsewhere (Martin et al., 2010).

The major progress in recent years in the pathophysiology of skin allergy was the demonstration that, although the established skin lesions are very diverse in terms of cellular composition (Th1, Th2, Th17, Tc1), CD8 ${ }^{+}$cytotoxic T lymphocytes (CTLs) are mandatory for the development of skin inflammation induced by either chemicals or protein allergens and are responsible for eczema and drug allergies (Vocanson et al., 2009; Hennino et al., 2007). Priming of CTLs occurs in lymph nodes (LNs) and is under the control of $\mathrm{CD}^{+}{ }^{+} \mathrm{T}_{\text {regs. }}$ Specific CTLs are the first cells to infiltrate the skin before that of $\mathrm{CD}^{+}$effector T-cells. CTLs induce activation and apoptosis of keratinocytes, which present the antigen and therefore are the targets of CTLs. Other leukocytes, including $\mathrm{CD}^{+}{ }^{+}$effector T-cells and $\mathrm{CD}^{+}{ }^{+} \mathrm{T}_{\text {reg }}$, are recruited later by inflammatory signals generated from the CTLmediated activation of skin cells. The new findings support a concept of $\mathrm{CD}^{+}$CTLs as pioneer cells that induce an initial inflammatory response in the skin in ACD, atopic eczema, and drug allergies. This has been mostly overlooked since immunohistology performed, e.g., at 48 hours after the contact allergen challenge often clearly reveals a $\mathrm{CD} 4^{+} \mathrm{T}$-cell dominated infiltrate. In the first hours after exposure, however, $\mathrm{CD}^{+} \mathrm{T}$-cells can be detected in the skin (Akiba et al., 2002).

At the moment, most studies use the mouse CHS model or a model for atopic eczema. Mice are sensitized by epicutaneous exposure to allergens (both haptens and proteins) without adjuvant and are challenged 5 days later. When mice are sensitized with strong contact allergens (DNFB, 2,4-dinitrofluorobenzene), they develop an acute skin inflammation starting after 24 hours and resolving spontaneously within a week. Mice deficient in $\mathrm{CD}^{+} \mathrm{T}$-cells (either because they are MHC class I-deficient or following $\mathrm{CD}^{+} \mathrm{T}$-cell depletion) cannot develop skin allergy, showing that $\mathrm{CD}^{+} \mathrm{T}$-cells are effector cells. In contrast, mice deficient in MHC class II or acutely depleted in CD4 ${ }^{+} \mathrm{T}$-cells develop an exaggerated CHS with no tendency to spontaneous resolution, showing that $\mathrm{CD}^{+}{ }^{+} \mathrm{T}$-cells contain regulatory cells (Kehren et al., 1999).

This model has been proved effective with strong allergens. The applicability was extended to weak allergens, such as fragrances or drugs (Vocanson et al., 2006). Here again, CD8 ${ }^{+}$ T-cells mediate the allergic response, but the situation is quite different. Normal mice develop skin inflammation only if all $\mathrm{CD} 4^{+}$cells are depleted to permit the priming of $\mathrm{CD}^{+} \mathrm{T}$-cells. Depletion of only the $\mathrm{CD}^{+}{ }^{+} \mathrm{T}_{\text {reg }}$ is not sufficient. On the other 


\section{contact sensitizer}

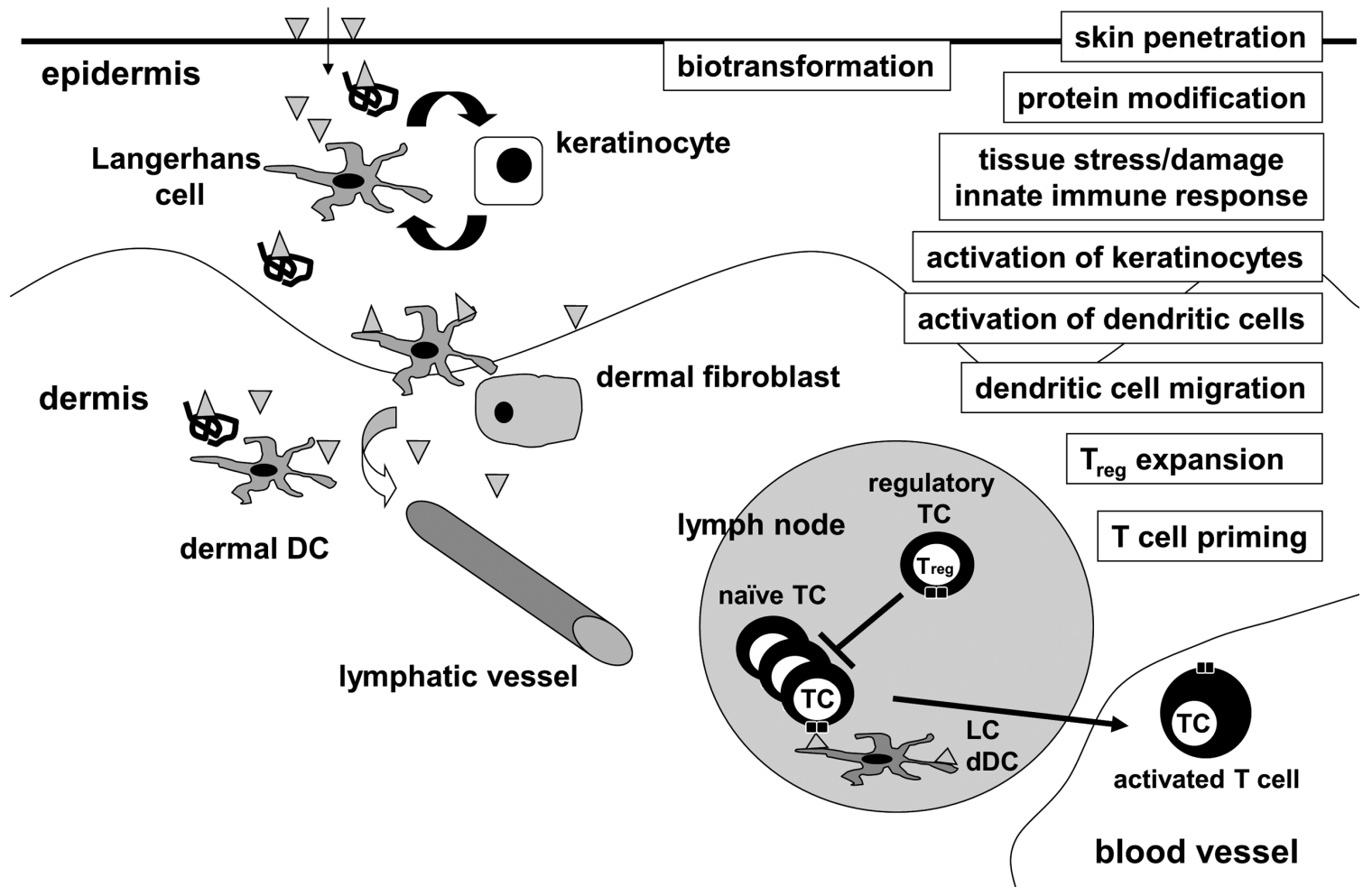

Fig. 1: General scheme for the sensitization process

hand, when $\mathrm{CD}^{+} \mathrm{T}$-cells are depleted the skin inflammation in the mice is abolished. The conclusion is that in the case of weak haptens, normal mice, like humans, are naturally tolerant and $\mathrm{CD}^{+}{ }^{+}$cells behave as tolerogenic cells of skin allergy. These regulatory $\mathrm{CD}^{+}{ }^{+}$cells do not contain only $\mathrm{T}_{\text {reg }}$ cells but most likely $\mathrm{CD} 4^{+} \mathrm{NKT}$ cells as well, which can exert a regulatory function as shown in oral tolerance to nickel in the CHS model.

At this stage, the conclusion is that $\mathrm{CD} 8^{+} \mathrm{T}$-cells mediate skin allergy without the need of CD4+ T-cell help. CD4 ${ }^{+} \mathrm{T}$-cells and $\mathrm{CD} 4^{+} \mathrm{NKT}$ cells are regulatory by controlling both priming and effector functions of $\mathrm{CD}^{+}$T-cells (Vocanson et al., 2010).

\section{Chemical aspects of sensitization}

Chair: E. Corsini

Most chemical allergens are less than $1000 \mathrm{Da}$ and are electrophilic or hydrophilic; as such they act as haptens and have to form a stable link with carrier proteins to form a complete allergen. Some of them are not inherently allergenic and must undergo metabolic transformation before participating in an al- lergic response. Chemistry is believed to be at the base of the chemical-induced sensitization (Fig. 1). The very first step of an allergic reaction is the chemical binding of the electrophilic hapten or an activated pre/prohapten to nucleophilic amino acids. As a consequence, many chemical families share a very similar mechanism while inducing ACD. The Sens-it-iv team (Casati et al., 2009) selected a set of chemicals representing the various chemical families for the development of new methods and to help the optimization of the final protocols (Tab. 1).

Are all chemical sensitizers identical?

Consequences for the development of alternative methods (by Jean-Pierre Lepoittevin)

The history of studies about the relationship between chemistry and sensitization started many years ago when Landsteiner and Jacobs (1936) published a paper about the sensitizing capacity of halo-nitrobenzene derivatives. Of course many issues have been unraveled since that paper, and it is now evident that the first step for a chemical substance (hapten) to trigger a sensitization reaction is the binding to a protein through stable covalent bonds (chemicals) or coordination bonds (metals). 
Tab. 1: Sens-it-iv selection of chemicals for the development and evaluation of in vitro methods for skin sensitization testing

\begin{tabular}{|c|c|c|c|}
\hline Chemical & CAS number & $\begin{array}{l}\text { hypothetical chemical reaction } \\
\text { involved in sensitization process }\end{array}$ & LLNA classification \\
\hline \multicolumn{4}{|l|}{ Respiratory positive controls } \\
\hline Diphenylmethane diisocyanate (MDI) & $101-68-8$ & & \\
\hline Trimellitic anhydride (TMA) & $552-30-7$ & & moderate \\
\hline Ammonium hexachloroplatinate (HCP) & $16919-58-7$ & & \\
\hline Hexamethylenediisocyanate & $822-06-0$ & & \\
\hline Maleic anhydride & $108-31-6$ & & \\
\hline Glutaraldehyde & $111-30-8$ & & \\
\hline \multicolumn{4}{|l|}{ Skin positive controls } \\
\hline 2,4 Dinitrochlorobenzene (DNCB) ** & $97-00-7$ & aryl electrophile & extreme \\
\hline Cinnamaldehyde & $104-55-2$ & Michael acceptor and/or Schiff base former & moderate \\
\hline Tetramethyl thiuram disulfide (TMTD) ** & $137-26-8$ & special reaction at Sulfur atom & moderate \\
\hline Resorcinol & $108-46-3$ & & weak \\
\hline Oxazolone & $15646-46-5$ & acyl transfer agent & extreme \\
\hline Glyoxal & $107-22-2$ & Schiff base former & moderate \\
\hline 2-Mercaptobenzothiazole (MBT) & $149-30-4$ & acyl transfer agent & moderate \\
\hline 2-Bromo-2-(bromomethyl) glutaronitrile & $35691-65-7$ & Michael acceptor & strong \\
\hline 4-Nitrobenzylbromide & $100-11-8$ & electrophile & extreme \\
\hline \multicolumn{4}{|l|}{ Skin positive controls (Pre/Pro-haptens) } \\
\hline Isoeugenol ** & $97-54-1$ & pro-hapten & moderate \\
\hline Eugenol ** & $104-55-2$ & pro-hapten & weak \\
\hline Cinnamic alcohol & $137-26-8$ & pro-hapten & weak \\
\hline Paraphenylendiamine (PPD) & $108-46-3$ & pro-hapten & strong \\
\hline \multicolumn{4}{|l|}{ Skin negative controls } \\
\hline Sodium lauryl sulphate (SLS) & $151-21-3$ & irritant & weak \\
\hline Salicylic acid (SA) & $69-72-7$ & & non sensitizer \\
\hline Phenol & $108-95-2$ & corrosive & \\
\hline Glycerol & $56-81-5$ & & non sensitizer \\
\hline Lactic acid & $50-21-5$ & & non sensitizer \\
\hline Chlorobenzene & $108-90-7$ & & non sensitizer \\
\hline p-Hydroxybenzoic acid & $99-96-7$ & & non sensitizer \\
\hline Benzaldehyde & $100-52-7$ & & non sensitizer \\
\hline Diethyl phthalate & $84-66-2$ & & non sensitizer \\
\hline Octanoic acid & $124-07-2$ & & non sensitizer \\
\hline
\end{tabular}

** These chemicals are also respiratory negative controls. 
<smiles>[Y]CNC(=O)C([R])NC(=O)CC</smiles>

$$
\begin{array}{ccc}
\text { Lysine } & \text { Cysteine } & \text { Methionine } \\
\mathrm{R}=-\left(\mathrm{CH}_{2}\right)_{4}-\mathrm{NH}_{2} & \mathrm{R}=-\mathrm{CH}_{2}-\mathrm{SH} & \mathrm{R}=-\left(\mathrm{CH}_{2}\right)_{2}-\mathrm{S}-\mathrm{CH}_{3}
\end{array}
$$

Histidine

Arginine

Tyrosine<smiles>P=Cc1cnc[nH]1</smiles>

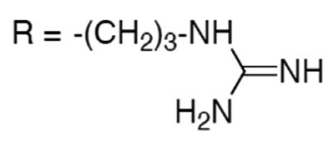<smiles>[R]Cc1ccc(O)cc1</smiles>

Fig. 2: Nucleophilic amino acids that may react with haptens

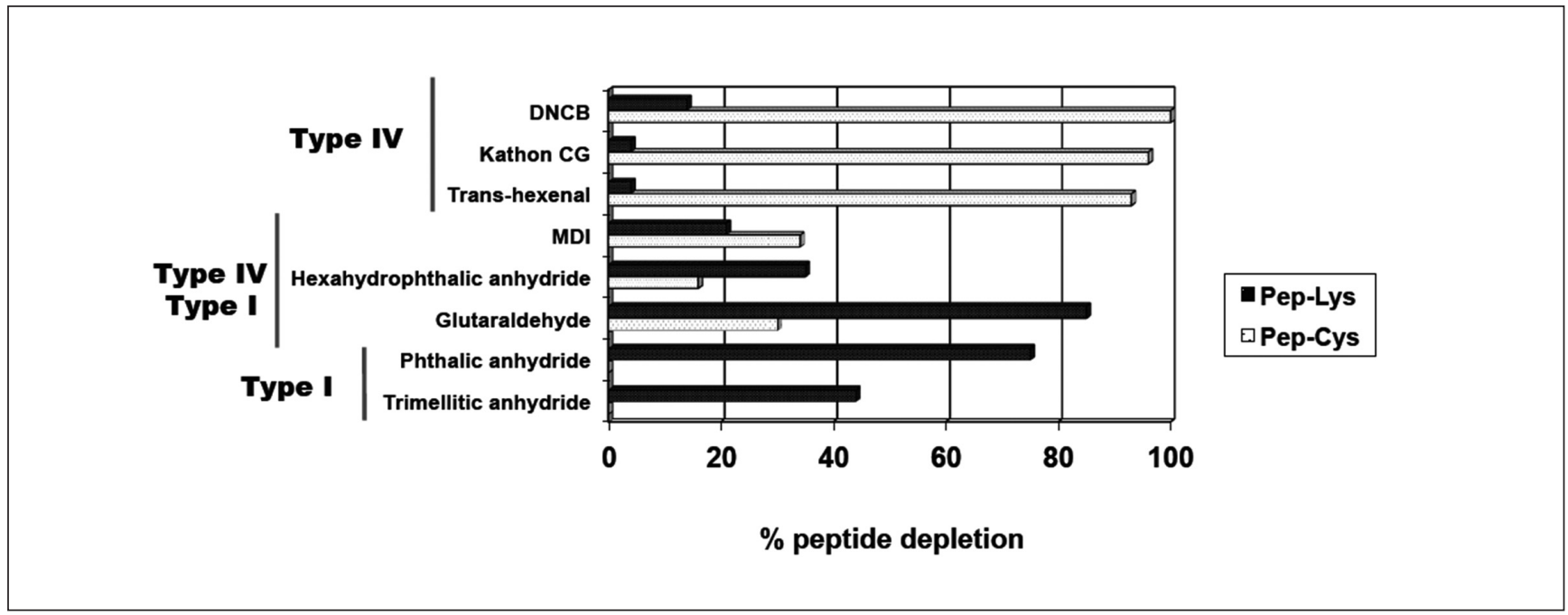

Fig. 3: Difference in reactivity towards Lysine (amino group) and Cysteine (thiol moiety), showing a dependence on the sensitization type that is triggered

The study of chemical reactivity in the sensitization process has driven the development of new models that are defined as "in chemico."

Chemical allergens generally are recognized to be electrophilic in nature, and they may react with nucleophiles (Fig. 2) to form stable covalent bonds. While any amino acid containing nucleophilic functional groups may contribute to the definition of the allergen reactivity profile, good models have been developed by assessing only the reactivity with the thiol and the amino groups, which are considered the main reactive sites (Gerberick et al., 2004). The Direct Peptide Reactivity Assay (DPRA) is based on measurement of the reactivity of the hapten with two different peptides containing, respectively, lysine and cysteine amino acids. The principle of the method is an HPLC-UV analysis to measure the peptide depletion after incubation with the substance to be tested. The problem, and probably the advantage, associated with this choice of target amino acids is that not all chemical sensitizers can be detected equally with one single reactive amino acid (Gerberick et al., 2007a,b; Fleischel et al., 2009). It seems that the preference of a chemical to react with one or the other drives the type of response that is activated in vivo. In particular, the reaction with lysine seems more associated with a Type I sensitization response (Th2 profile) and the reaction with cysteine with a Type IV response (Th1 profile). Is that a clue for a new model? This is very difficult to say at this stage of the research, even though it offers a promising opportunity (Fig. 3).

The efficacy of DPRA has already been demonstrated effective in the detection of allergens, and this method is now following the validation procedure at ECVAM. All substances that need a chemical modification to become active allergens, i.e., pre/ 


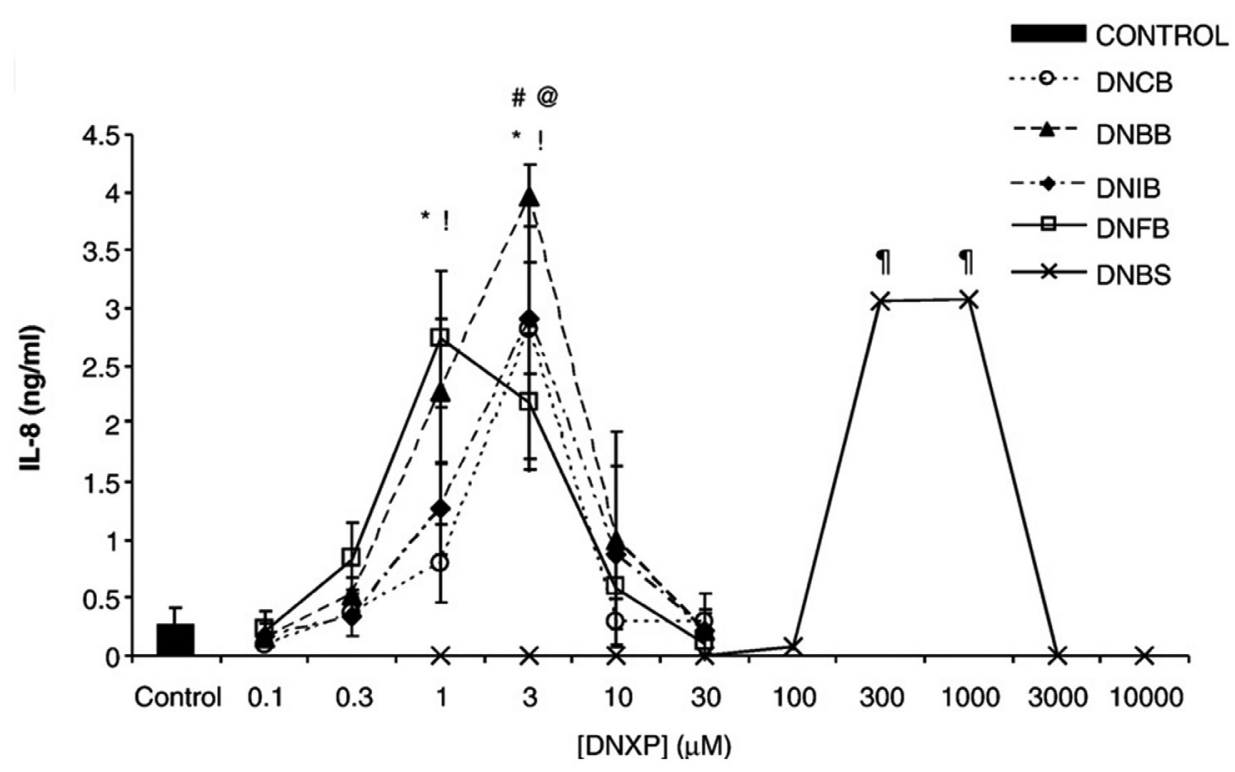

Fig. 4: Release of IL-8 in THP-1 cells treated with different dinitrohalogen(X) benzenes (DNXP)

DNCB: dinitrochlorobenzene, DNBB: dinitrobromobenzene, DNIB: dinitroiodobenzene, DNFB: dinitrofluorobenzene,

DNBS: dinitrobenzene sulfonic acid. The latter is not a real DNXB and, in fact, it demonstrates a different profile

pro-haptens, remain out of the applicability domain of DPRA. To overcome this limitation, the possibility has been evaluated to add an incubation step with horseradish peroxidase and hydrogen peroxide (HRP/P). This system has proven effective to catalyze the conversion via oxidation of the non-reactive chemical sensitizer to a reactive (electrophilic) chemical that can then form adducts with a nucleophile containing peptide and mimic the activation of a xenobiotic in nature by both natural (metabolic) and atmospheric agents (oxygen) (Gerberick et al., 2009). The HRP/P enzymatic system provides a straightforward approach for detecting the peptide reactivity of many well-known pro-haptens via an enzyme-mediated oxidative process.

\section{Qualification of antigen formation in vivo}

and in vitro to define the immunogenicity of drugs and

chemicals (by Kevin Park)

The hypothesis was presented that conjugation of the hapten to the protein to form an antigen is the basis for a hypersensitivity reaction in susceptible individuals after a second exposure. In order to better understand the mechanisms of the triggering process, the family of dinitrohalobenzenes (DNXB) was studied in detail. The whole flow of effects was assessed in THP-1 cells by considering, in particular, IL- 8 release, irreversible protein binding, and p38 MAPK activity. Data about other parameters are described elsewhere (Megherbi et al., 2009).

DNXB activates THP-1 cells by up-regulating CD54 and inducing the release of IL-8 (Fig. 4) when applied at a noncytotoxic concentration, i.e., below the concentration of $30 \mu \mathrm{M}$.
This experiment showed that there is no difference in potency among the representatives of the chemical family, even though upregulation of CD54 by DNFB starts at a lower concentration than observed for the other members of the family. An increased irreversible binding to cellular proteins seems to confirm a relationship with potency, and it seems that this binding occurs in a selective manner. This is also correlated to the increased activation of p38 MAPK, as it was measured as a function of both concentration and duration of the exposure.

This important principle may be applied in the area of new drug investigation, where a tool is required to identify if a drug is a potential hapten.

\section{Role of skin metabolism and transport in allergic contact dermatitis (by Jens Baron)}

Human skin has an important physiological role as a protective barrier for the organism. This is achieved through a simple physical barrier that prevents entrance into the organism from biological assault (bacteria, fungi, and viruses), physical assault (UV-radiation, mechanical injuries) and chemical assault (irritants, allergens). In the opposite direction, the main function is the prevention of water loss and desiccation. However, it is well known that the function of the skin is not only mechanical; there is also intense activity of enzymes working as transporters in cells in both directions (in and out), plus a metabolic activity in the epidermis.

Most xenobiotics are not chemically reactive enough to bind to high molecular weight compounds spontaneously, and they 
trigger no immunological reactions. Some of them, in particular weak contact sensitizers, are transformed into highly reactive species. It has been shown that the epidermis possesses multiple cytochrome P450 (CYP) isoenzymes that are able to metabolize xenobiotics to these highly reactive species (Baron et al., 2001). These enzymes are present in keratinocytes, which are the main cells of the epidermis, but they also are present in antigen presenting cells such as monocytes or dendritic cells.

Liver microsomes, hepatocytes, or liver tissue samples are commonly used to study xenobiotic metabolism. However, the metabolic activity of the liver differs both qualitatively and quantitatively from the skin, as different CYP enzymes are expressed in the two tissues. RNA expression measured by PCR analysis revealed a significant expression of CYP1A1, 1B1, 2B6, 2E1, and 3A5, as well as a weak expression of CYP 2B6 (Bergstrom et al., 2007). Another very important issue to be considered is the direct induction of CYP expression by prohaptens when they come in contact with the dendritic cells in the epidermis. Detailed studies (Bergstrom et al., 2007; Hagvall et al., 2008) have demonstrated that metabolic activation explains why apparently non-electrophilic molecules such as geraniol and cinnamic alcohol can be transformed into more potent allergens. In terms of developing relevant in vitro methods, another important question concerns whether dendritic cell-like cell lines have similar metabolic capacities compared to primary dendritic cells. Further investigation is required in this area, but it seems that, at least qualitatively, the types of metabolites are the same, even if relative quantity may be variable.

Metabolism of pro-haptens occurs in the cells. Efflux and influx enzymes, which may differ in keratinocytes, dendritic cells, and so on, actively mediate the transport of allergens into and out of the cells.

One important super-family of active membrane transporters is the family of ATP-binding cassette (ABC) transport proteins that use the energy of ATP hydrolysis to efflux substances across a membrane against a concentration gradient. Recent studies revealed that $\mathrm{ABC}$ transporters not only have a protective function related to their capacity to extrude toxic compounds but also have additional regulatory functions of these transport systems on immune cells (Ott et al., 2010).

The multidrug resistance related proteins (MRP, gene name: ATP-binding cassette $\mathrm{C}$ transporters, $\mathrm{ABCC}$ ) are a subfamily of $\mathrm{ABC}$ transporters and consist of at least seven members. Concerning the regulatory mechanisms of these transport proteins in skin cells, it was demonstrated that IL-6 type cytokines significantly enhance the expression of different MRPs in epidermal keratinocytes. Expression of several efflux proteins has been detected in various skin cells. Their role in ACD seems to be the export of CYP converted pro-haptens.

\section{From pathways to markers and from markers to pathways}

Chair: M. Lindstedt

Molecules and signaling pathways involved in allergic reactions have been investigated through -omic based approaches applied to keratinocytes and dendritic cells. The projects have focused on biomarker identification, using proteomics and genome-wide transcriptomics for the purpose of using the biomarker profiles, or signatures, as readout in novel assays that are able to discriminate between non-sensitizers, irritants, and skin or respiratory sensitizers with highest accuracy. The biomarker profiles resulting from the -omics technologies also provide important information about molecular mechanisms and signaling pathways underlying the adverse effects of chemical allergens. This mechanistic understanding provides confidence that the identified signature is relevant for human safety and represents a novel contribution from these new global in vitro approaches.

\section{Proteomics response signatures, pathway mapping,}

and prototype mass spectrometric assays for skin sensitization testing (by Petra Budde and Hermann-Josef Thierse)

Proteomics applied to skin sensitization delineates the cellular response to a specific chemical allergen at the protein level. It is reasonable to assume that different classes of chemical sensitizers may trigger different cellular response pathways in vitro. By performing comprehensive in-depth protein profiling of different in vitro skin sensitization cell models, proteomics can reveal valuable information about biomarker signatures related to the molecular mechanisms of skin sensitization and help generate knowledge for better risk assessment of potential new sensitizers.

For this project, it was decided to screen for proteomic response profiles of MUTZ3, a human surrogate dendritic cell model, and human primary keratinocytes exposed to chemical sensitizer, non-sensitizer, and vehicle controls using quantitative LC-MS/MS. Further details on the method can be found at http:// www.sens-it-iv.eu/files/newsletter/Sens-it-iv_Newsletter_38. html (accessed February 11, 2012).

After a discovery phase that was based on the analysis of 700 proteins, protein signatures were developed in keratinocytes and MUTZ3 cells comprising, in total, 200 proteins involved in antigen presentation, inflammation, and stress response pathways. Subsets of biomarkers were found to contain extracellular proteins opening for the development of protein array-type of assays.

Targeted and multiplexed mass spectrometric assays based on selected reaction monitoring (SRM) were developed to verify the eight best performing biomarkers in MUTZ3 cells. The Sensiderm SRM assay was capable of discriminating sensitizers, irritants, and controls. Compared to the classical ELISA approach, the development of the Sensiderm SRM assay was performed in shorter time and allowed simultaneous and consistent measurement of a set of eight biomarkers. Thus, verification of biomarker signatures should be much more straightforward.

It was concluded that SRM-based assays allow for combinations of protein markers belonging to different pathways of interest and that in future this test format could provide additional information on pathways triggered by unknown chemicals.

\section{Qualitative and quantitative allergen-specific protein} profiles as matrices for next generation assay development (by Hermann-Josef Thierse)

The Sens-it-iv project contributed fundamentally to a better basic understanding of early disease processes in ACD, as well as 
to the development of next generation immunoproteomic predictive in vitro assays.

Since haptenation is essential for T-cell mediated allergic immune responses, a novel immune-proteomic platform assisting in the quantification of chemical-self protein interactions in human antigen presenting cells and human skin cells (keratinocytes) was considered. More than 100 allergen interacting proteins were identified and currently are integrated into a promising new proteomic allergen-peptide/protein interaction assay (APIA) (Dietz et al., 2012; Heiss et al., 2005; Thierse et al., 2004).

Numerous quantitative differential proteomic discovery analyses were performed to search for (so far) unknown allergen-specific (non-irritant) functional signaling/metabolic pathways. By using MALDI-MS technology, numerous predictive proteomic patterns were identified in the dendritic cell-like cell line MUTZ3 cells, and human keratinocytes. Analysis of human skin cells resulted in the discovery of 100 potential markers out of 184 skin cell samples generated by the experimental design. These results are now ready to be used for the development of new commercial in vitro assays.

Proteomic-based technologies were applied for targeting chemical-specific human T-cell epitopes and for supporting quality control experiments in the establishment of a novel human T-cell priming assay (hTCPA) for the identification of contact allergens (Dietz et al., 2010; Martin et al, 2010; Richter et al., 2012). These technologies have provided new opportunities for the development of assays for tracking molecular and cellular allergen-protein interactions (Thierse, et al., 2007), as well as for differential proteomic analyses in human skin cells activated by human allergens (Dietz et al., 2009).

\section{Sensitization pathways identified by genomics}

in MUTZ-3 cells (by Ann-Sofie Albrekt)

Through analysis of pathway data from a genomic study of MUTZ-3 cells stimulated with sensitizers and negative chemicals, current theories about skin sensitization were confirmed and, more importantly, novel theories suggested. The work is an extension of the work done to identify the Genomic Allergen

Tab. 2: Top 5 pathways found in genomics of MUTZ-3 cells following stimulation with skin sensitizing chemicals

\begin{tabular}{|l|c|}
\hline Pathway & $\begin{array}{l}\text { Number of GARD } \\
\text { genes involved } \\
\text { in pathway }\end{array}$ \\
\hline NRF2 mediated oxidative response & 10 \\
\hline Xenobiotic metabolism signaling & 8 \\
\hline $\begin{array}{l}\text { LPS/IL-1 mediated inhibition } \\
\text { of RXR function }\end{array}$ & 6 \\
\hline Aryl hydrocarbon receptor signaling & 6 \\
\hline Protein kinase A signaling & 6 \\
\hline
\end{tabular}

Rapid Detection (GARD) test (Johansson et al., 2011). Analyzing the differential pathway usage of the 18 sensitizing chemicals in the study, it was shown that 6 pathways, 5 of which were previously known to be involved in responses to xenobiotics (Tab. 2 ), were most heavily affected. For example, the Keap1/NRF2 mediated antioxidant response is highly regulated by many sensitizers, confirming current theories of skin sensitization. While the NRF2 mediated oxidative response pathway was the most generally affected pathway, it was clear that this pathway is only one in a range of pathways affecting cellular functions. This was clearly demonstrated by pathway clustering, showing that groups of chemicals downregulate specific signaling pathways, e.g., metabolic or cell cycle functions, while other groups upregulate the same set. It is important to note that this was the first time that different categories of chemicals were represented by different combinations of pathways, suggesting that pathway profiling of unknown chemicals can provide information about, e.g., the sensitizing potency of the chemical.

\section{From theory to practical assays}

The final goal of the Sens-it-iv project was the development of one or more methods for the identification of contact sensitizers and the assessment of their sensitization potential. The level of development was intended to be at a level to enter the prevalidation phase. In this term, the project has been truly successful, producing many interesting methods in a highly advanced stage. In addition, many other methods are very promising, even though more refinement is required.

Other tests, though not yet at a stage to be used in screening assays, have contributed considerably to the mechanistic understanding of allergic sensitization and individualized responses within the human population.

Assays that have been developed outside the boundaries of the Sens-it-iv project also have been considered. The current section briefly addresses these advanced tests and reflects on their status.

\subsection{Assays developed outside Sens-it-iv Chair: P. Aeby}

\section{Overview of the Cosmetics Europe (formerly Colipa)} assay development program (by Pierre Aeby)

Cosmetics Europe (The European Cosmetics Industry Trade Association) funds an international research program to develop and evaluate new non-animal test methods for skin sensitization risk assessment. Its ongoing research portfolio continues to provide new insights into the biological processes driving skin sensitization, with the goal of defining a toolbox of non-animal test methods capable of characterizing skin sensitizer potency without the need for new animal test data (Aeby et al., 2010; Maxwell et al., 2011; Goebel et al., 2012).

One of the research projects is investigating the connection between the reactivity of molecules towards nucleophiles and their sensitizing potential, and it is expected to clarify the link 
between chemical reactivity and NRF2 activation. Another research project is analyzing the role of the innate immune response, more specifically the response of stressed keratinocytes or monocytes and their recognition by NK/NKT cells. Finally, a third research project is looking at a possible correlation between the strength of contact allergens, effector and regulatory T-cell frequency, and T-cell receptor repertoire.

On the development side, a project was set up to evaluate the response of dendritic cells upon in vitro exposure to contact sensitizers, the goal being the development of a multi-parameter dendritic cell biosensor system based on signature gene expression and the production of reactive oxygen species (ROS assay). Another project concerns the development of a human T-cell priming assay (hTCPA) for the in vitro screening of contact allergens. This assay is based on T-cells depleted in $\mathrm{T}_{\text {reg }}$ cells in order to increase its sensitivity.

In silico approaches also are included in the range of methods that have been developed and currently are being evaluated by the Cosmetics Europe Skin Tolerance Task Force. In particular, a computational model has been developed for calculating both the permeation and skin concentrations of topically applied compounds. It is a one-dimensional model programmed as an Excel $^{\mathrm{TM}}$ spreadsheet that can simulate the delivery step in an LLNA or human sensitization assay and predict the concentration of chemicals in the viable epidermis following a finite dose application of chemicals.

Finally, Cosmetics Europe member companies have developed three in vitro tests that have been accepted by ECVAM to enter the formal validation process and are already at the final stage: Direct Peptide Reactivity Assay (DPRA), Human Cell Line Activation Test (h-CLAT), and Myeloid U937 Skin Sensitization Test (MUSST). Each test had previously undergone in-house and inter-laboratory evaluation to optimize and fix protocols, evaluate protocol transferability, characterize accuracy of prediction, and define the applicability domain.

In a next phase, Cosmetics Europe is planning to evaluate the performance of 16 non-animal test methods developed within and outside of its program, e.g., KeratinoSens (Givaudan), VITOSENS (Vito), SenCeeTox (CeeTox), the PBMDC assay (Beiersdorf), the NCTC 2544 IL-18 assay (University of Milano), the AREc32 assay (CXR Biosciences), the tiered approach (VU Medical Center), the GARD gene signature assay (Lund University), and also the assays already submitted for ECVAM pre-validation (DPRA, MUSST, and h-CLAT). The goal of this method evaluation program is the definition of a non-animal toolbox capable of replacing the need for animal test data for consumer safety risk assessment. However, there are still some gaps in this project portfolio: We need to better understand skin bioavailability, metabolism, and the mechanism of the human T-cell response to haptens. Further research and development projects covering these gaps should be identified and sponsored.

The development and utility of peptide reactivity assays for screening contact allergens (by Petra Kern)

The Direct Peptide Reactivity Assay (DPRA) is one of the most advanced methods to measure reactivity towards amino acids in order to support sensitization prediction in vitro. It is at the final stage of the validation process at ECVAM. The principle is very simple, and it is based on the evidence that there is a clear association between the degree of chemical reactivity and the sensitization potency of a chemical sensitizer (Gerberick et al., 2004). At the beginning of method development, the amino acids lysine, cysteine, and histidine, and the protein GSH were assessed. The method is based on determining peptide depletion after binding to a chemical rather than measuring the formation of an adduct that is not unique in many cases. Several analytical techniques can be used: the assay in validation is based on LC-UV, even though MS detector is also accepted and even preferred. For the DPRA, a prediction model was developed, grouping materials into various classes based on their reactivity potential. The developed model is based on a classification tree analysis, which showed that reactivity towards both cysteine and lysine is needed to obtain a good correlation with biological data. The threshold for low/minimal reactivity is set at $6.38 \%$ (combined depletion of Cys/Lys) and at a higher percentage of peptide depletion for moderate or high reactivity chemicals. Using this decision tree model, the accuracy of the predictivity with a large dataset of 157 chemicals was $81 \%$ in comparison with LLNA data (just comparing yes/ no sensitizer). In addition to hazard identification (yes/no), the evaluation of the correlation between reactivity and sensitizing potency of chemicals seems promising (Gerberick et al., 2007b).

Currently, there is ongoing research to further improve the DPRA by incorporating an oxidative activation step in order to allow for the identification of pro-haptens as well (Gerberick et al., 2009; Troutman et al., 2011) (Fig. 5), which did not show any activity in the DPRA so far.

Despite evidence of some good correlation of reactivity with biological data, the application of peptide reactivity assays such as the DPRA has to be seen in the context of an integrated testing strategy for predicting skin sensitization potential. As an example of an integrated testing strategy to determine sensitization potential, a Bayesian network (BN) was applied to predict the probability of a chemical to be within a certain potency class (non, weak, moderate, strong) by combining heterogeneous data derived from in chemico, in vitro, and in silico methods. One also can decide upon the best testing flow, which is then optimized for each single chemical (Jaworska et al., 2011). The results clearly demonstrate that there is no one best in vitro method or no one best test sequence, but rather the individual testing strategy depends on chemical structure, exposure, and initial information.

\section{The myeloid U937 skin sensitization test (MUSST)}

for prediction of skin sensitization potential (by Silvia Teissier) This method focuses on the assessment of cosmetic ingredients and the need to have not only hazard identification but also potency information for risk assessment. Testing is performed on the U937 cell line, and CD86 is the only marker that is measured by flow cytometry together with cell viability. The prediction model is very easy, and it is defined by the stimulation index (SI) observed with cells treated with the chemical 


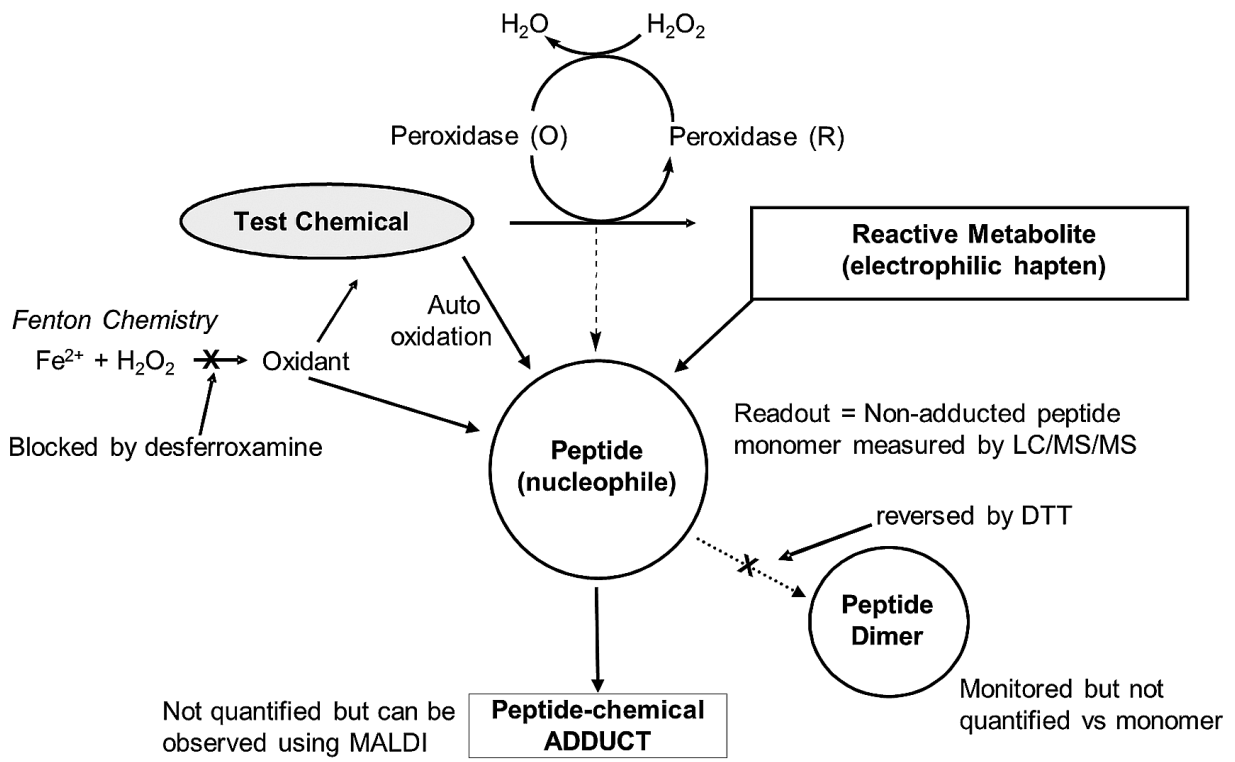

Fig. 5: Scheme for the modified version of DPRA to incorporate an activation step for identifying pro-hapten chemical sensitizers by peroxidase reaction

Peptide depletion is measured, and the formation of adducts is observable by MALDI, even if quantitation is not possible.

as compared to cells treated with the vehicle. The SI must be above 150 with a dose response relationship and at least two concordant experiments out of three, with a rather low minimal cell viability of $70 \%$ opening up for U937 cell responses to cell debris instead of the chemical.

The assay has successfully passed the pre-validation process with three laboratories, and it is now under validation at ECVAM. So far, the assay has been challenged with 165 internal chemicals and has demonstrated a specificity of $67 \%$, a sensitivity of $85 \%$, and accuracy of $78 \%$ (Maxwell et al., 2011). These results indicate that the MUSST assay has to be combined with other models (e.g., in a statistical approach or testing strategy).

The human cell line activation test ( $h$-CLAT) for assessing skin sensitization potential (by Takao Ashikaga and Hitoshi Sakaguchi)

The human Cell Line Activation Test (h-CLAT) uses THP-1 cells and a human monocytic leukemia cell line, and it is based on the mechanism of dendritic cell activation (Ashikaga et al., 2006; Sakaguchi et al., 2006). The levels of CD86 and CD54 expression on the surface of THP-1 cells are determined following 24 hours of chemical exposure. The h-CLAT showed good predictive capacity and intra-/inter-laboratory reproducibility, and it is regarded as a useful and robust cell-based in vitro skin sensitization test (Ashikaga et al., 2008; Sakaguchi et al., 2010).

The principle of the h-CLAT method is based on the culture of the THP- 1 cells with test chemicals at 8 concentrations, based on cell viability of $75 \%$. After cell staining, the expression of CD86 and CD54 are measured by flow cytometric analysis. The relative fluorescence intensity (RFI) is calculated through the geometric mean fluorescence intensity (MFI). The threshold for positivity was set for CD86 at RFI $\geq 150 \%$ and/or RFI $\geq 200 \%$ for CD54, with a minimum viability of $50 \%$. The test chemical is considered positive if 2 out of 3 independent experiments at any dose exceed the threshold.

Following an extensive optimization of the protocol, the hCLAT was challenged by 117 chemicals previously characterized in the mouse local lymph node assay (LLNA). The human response data also were available for many of them. The results of this study are presented in Figure 6, and further details are available (Ashikaga et al., 2010).

The predictive capacity is acceptable. Analysis of the few compounds that are incorrectly identified as negative indicated that the applicability domain of the h-CLAT does not include chemicals with a very poor water solubility (e.g., hexyl cinnamic aldehyde, abietic acid, phthalic anhydride) or chemicals that are pro(pre)haptens (e.g., benzoyl peroxide, geraniol, isoeugenol, abietic acid). Some very weak sensitizers (1-bromohexane, 


\begin{tabular}{l|c|c|c|}
\cline { 3 - 4 } \multicolumn{2}{|c|}{ h-CLAT vs LLNA } & \multicolumn{2}{c|}{ h-CLAT } \\
\cline { 2 - 4 } \multicolumn{2}{c|}{} & $+\mathbf{( 8 3 )}$ & $\mathbf{- ( 3 4 )}$ \\
\hline \multirow{2}{*}{ LLNA } & $\mathbf{+ ( 8 5 )}$ & $\mathbf{7 5}$ & $\mathbf{1 0}$ \\
\cline { 2 - 4 } & $\mathbf{- ( 3 2 )}$ & $\mathbf{8}$ & $\mathbf{2 4}$ \\
\hline Sensitivity: & $75 / 85(88 \%)$ \\
Specificity: & $24 / 32(75 \%)$ \\
Positive predictivity: & $\begin{array}{l}75 / 83(90 \%) \\
\text { Negative predictivity: }\end{array}$ \\
Accuracy: & $\begin{array}{l}\mathbf{9 9 / 1 1 7}(\mathbf{8 5} \%) \\
\text { Accur }\end{array}$
\end{tabular}

Fig. 6: Sensitivity and specificity of h-CLAT method compared with both LLNA and human data

cyclamen aldehyde, butyl glycidyl ether) cannot enhance the CD86/CD54 enough and are classified as false negatives.

There are indications that the h-CLAT correlates with the EC3 value of the LLNA and may have the potential to provide information about the potency of the test chemical. The minimum induction threshold (MIT) is defined as the smaller value of either EC150 or EC200, i.e., the minimum concentration of the test chemical that induces a RFI of 150 for the expression of CD86 or 200 for the expression of CD54.

The border between strong and weak sensitizers that has recently been set in the EU CLP (Classification, Labeling and Packaging Regulation) at the LLNA EC 3 value of 2 corresponds to a MIT in the h-CLAT of $13 \mu \mathrm{g} / \mathrm{ml}$ (Nukada et al., 2012).

\section{In vitro detection of contact allergens: Development} of an optimized protocol and performance of an international ring study using human peripheral blood monocyte derived dendritic cells (by Hendrik Reuter)

For the development of a new in vitro assay to detect skin sensitization potential of chemicals, peripheral blood monocytederived dendritic cells (PBMDC) are a valid alternative to dendritic-like cell lines such as THP-1 or U937. The advantages of these cells include that they are true human-like cells without significant genomic degeneration, and they display most of the normal physiological and metabolic capacity of functional dendritic cells. The drawback of using PBMDC includes the difficulty of collecting human blood and the inherent donor-todonor variability that may impair the applicability of the derived method.

These pros and cons were elegantly balanced in a robust method for detecting skin sensitizers (Reuter et al., 2011). The general procedure of the method is summarized in Figure 7. After isolating of CD14 enriched monocytes, differentiation is achieved by incubation with IL-4 and granulocyte-macrophage colony stimulating factor (GM-CSF). IL-4 concentration is a critical parameter to obtain PBMDCs that are susceptible enough to be activated by sensitizers. Basal CD86 is controlled to select cells that are cultured with the test chemicals, and CD86 expression is determined using flow cytometry. The final outcome is expressed as difference to the vehicle controls. A chemical is considered a sensitizer if $\triangle \mathrm{CD} 86$ exceeds $20 \%$ with a corresponding cell viability of at least $80 \%$. In accordance with previously published data, cell viability was found to be an important parameter, as a significant increase in CD86 expression also is observed in response to the cell debris.

Each experiment is run on PBMDC derived from the same donor. It is important that the $\Delta \mathrm{CD} 86$ is calculated from blood coming from the same buffy coat. However, the analysis of basal CD86 expression was measured in 172 samples, demonstrating that donor to donor variability has a low impact on the robustness of the method.

The predictive capacity of this optimized method was assessed using 12 chemicals, including 4 non-sensitizers). Only one non-sensitizer (benzalkonium chloride) was misclassified as sensitizer. On the other hand, SDS that is generally considered a false positive in the LLNA is clearly negative.

As observed for other cell-based assays, this optimized PBMDC-based method appeared to provide information about the potency of the test chemical.

As a follow-up step, this method was successfully transferred to four labs that had no experience and used different equipment, demonstrating the efficacy of the optimized protocol and the real possibility of applying this assay on a routine basis for assessment of the sensitization potential of chemicals.

\section{VITOSENS ${ }^{\circledR}$ : a primary model with quantitative markers for skin sensitization (by Jef Hooyberghs)}

The VITOSENS ${ }^{\circledR}$ method is a cell-based model for identification of skin sensitization hazard. The strengths and uniqueness lie in the fact that it is based on human primary naïve, $\mathrm{CD} 34^{+}$ 


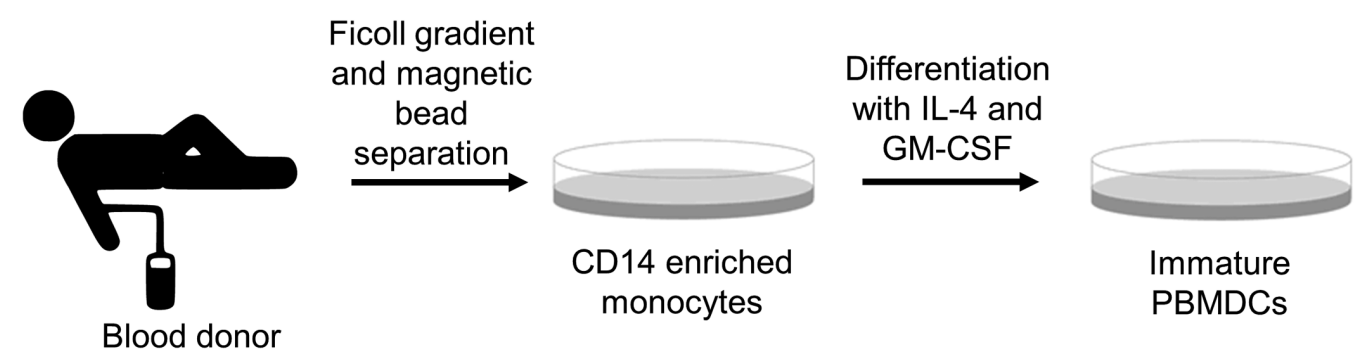

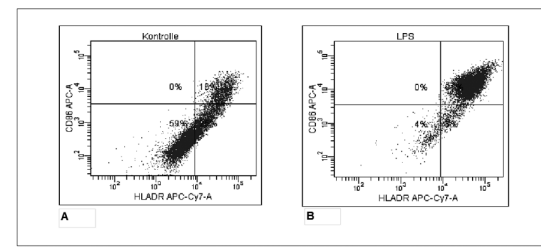

Analysis

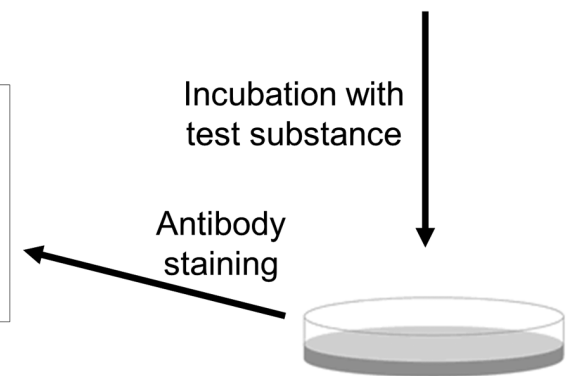

Activated PBMDCs

Fig. 7: Experimental setup of a PBMDC (peripheral blood monocyte-derived dendritic cells) method

Immature dendritic cells are isolated directly from donors' blood and incubated with the test substance.

derived dendritic cells and that the readout is a quantitative gene expression measurement. The $\mathrm{CD}_{3} 4^{+}$cells are extracted from the umbilical blood vessels of placentas of normal full-term babies. After differentiation toward immature $\mathrm{CD} 34^{+}$dendritic cells and culture for 6 hours with the test chemicals, the expression of 2 genes, cAMP responsive element modulator (CREM) and chemokine ( $\mathrm{C}-\mathrm{C}$ motif) receptor 2 (CCR2) are measured by RT qPCR. These genes were identified by microarray analysis as significantly altered by skin-sensitizing vs non-sensitizing chemicals (Schoeters et al., 2007).

Method optimization was achieved through exposure to 21 known chemicals (10 sensitizing vs 11 non-sensitizing chemicals) used at $20 \%$ cytotoxic concentration $\left(\mathrm{IC}_{20}\right)$ (Hooyberghs et al., 2008). Gene expression changes were determined as fold changes (FC), i.e., ratios of gene expression levels of exposed samples over corresponding solvent control samples. The results were promising with only one false negative (which could be explained by metabolic properties of the assay) and a final concordance of $89 \%$. Moreover, it demonstrated that there is a linear correlation between the VITOSENS ${ }^{\circledR}$ output and the EC3 measured by the LLNA, raising the possibility of applying the VITOSENS ${ }^{\circledR}$ method also for potency determination (Lambrechts et al., 2010a).

This model was studied in detail to gain an understanding of the role of the selected gene markers in the sensitization process, to ensure the theoretical validity of the approach, and to determine that they are non-responsive to non-allergenic inflammatory stimuli (Lambrechts et al., 2010b, 2011).

\subsection{The Sens-it-iv toolbox}

Chair: I. Nelissen and K. Park

\section{The NCTC2544 assay (by Emanuela Corsini)}

Keratinocytes play a key role in all phases of skin sensitization, and interleukin-18 (IL-18) was shown to play a proximal role in the induction of allergic contact sensitization by favoring Th- 1 type immune response through stimulation of pro-inflammatory mediators such as TNF- $\alpha$, IL-8, and IFN- $\gamma$, (Okamura et al., 1995; Cumberbatch et al., 2001; Antonopoulos et al., 2008). IL-18 production in the human keratinocyte cell line NCTC 2544 has been identified as a potentially useful endpoint for identification and discrimination of contact versus respiratory allergens and/or irritants (Corsini et al., 2009; Galbiati et al., 2011). In the context of the sensitization process, the NCTC 2544 assay was designed to cover the initial phase "local trauma" - proinflammatory cytokine production (danger signals), important for maturation and migration of dendritic cells, and T-cell activation.

The NCTC 2544 cell line is a commercially available skin epithelial-like cell line originating from normal human skin, which possesses a good expression of cytochrome P450-dependent enzymatic activities. Cells are incubated for 24 hours with three concentrations of the test chemicals, and IL-18 expression is measured by ELISA. The optimal readout is obtained at a cytotoxicity level of $80 \%$ (CV80). If the fold increase in intracellular IL-18 is greater than 1.2 and the increase in IL-18 is statistically significant compared to vehicle-treated cells, the chemical 
is classified as a contact sensitizer. For a given chemical, the same classification must be obtained in at least two out of three independent experiments. The 1.2 fold increase is observed for at least one of the concentrations tested. Respiratory sensitizers and irritants were consistently negative in this assay.

The analysis of 33 known chemicals led to protocol optimization, and most critical parameters were highlighted during a prevalidation exercise funded by the Dutch governmental funding agency ZonMW (Teunis et al., 2012).

\section{The Epidermal Equivalent (EE) potency assay (by Sue Gibbs)}

The Epidermal Equivalent (EE) model cannot distinguish sensitizers from irritants, but it may be a valuable tool for the classification of an identified contact sensitizer as extreme, strong, moderate, or weak. Identification of a chemical as a sensitizer can be determined by any of the tests described in this report. The test chemical is administered topically for 24 hours on a reconstructed epidermal equivalent. Sensitizer potency is related to penetration of stratum corneum and degree of cytotoxicity. The lower the concentration required to cause $50 \%$ decrease in cell viability (EE-EC50) or to obtain a 10-fold increase in IL-1 $\alpha$ secretion, the stronger the sensitizer (Dos Santos et al., 2011).

This model was challenged with 13 skin sensitizers, and the results were compared with both LLNA-EC3 values and human data obtained through a human repeat insult patch test (HRIPT). The preliminary results were considered sufficiently promising by the Dutch funding agency ZonMW to initiate a prevalidation study (Teunis et al., 2012). A number of test limitations were identified. The respiratory sensitizers of the study were negative in the test, probably due to their instability in water, resulting in degradation products known to be non-sensitizing. Other limitations were recorded with chemicals that were not soluble in the vehicle employed or that interfered with MTT (e.g., PPD, p-phenylen-diamine), and chemicals not showing sufficient cytotoxicity (no $\mathrm{EC}_{50}$ value available). Three chemicals were clear outliers, but reasons are still under investigation.

In order to consider the potential implementation of this in vitro assay on a broad scale, some commercially available reconstructed epidermis models (such as EST1000 ${ }^{\mathrm{TM}}$ and SkinEthic ${ }^{\mathrm{TM}}$ ) were evaluated and compared with the in house VUMC-EE that was used to develop the method. It was found that both cytotoxicity and IL- $1 \alpha$ secretion were higher after topical application of $1 \%$ DMSO (vehicle alone), leading to the conclusion that commercial EE have a slightly less competent barrier function. However, results with the extreme sensitizer DNCB and the moderate sensitizer resorcinol were comparable to the VUMC-EE model, also confirming the correlation with the LLNA-EC3 (Spiekstra et al., 2009).

\section{The DC migration assay (by Sue Gibbs)}

During the sensitization process, activated LCs migrate towards lymphatic vessels. This step is simulated in the MUTZ-LC migration assay (Ouwehand et al., 2008, 2010). The model is based on MUTZ-3 human cell lines that are differentiated for 7 days toward cells that closely resemble Langerhans cells.

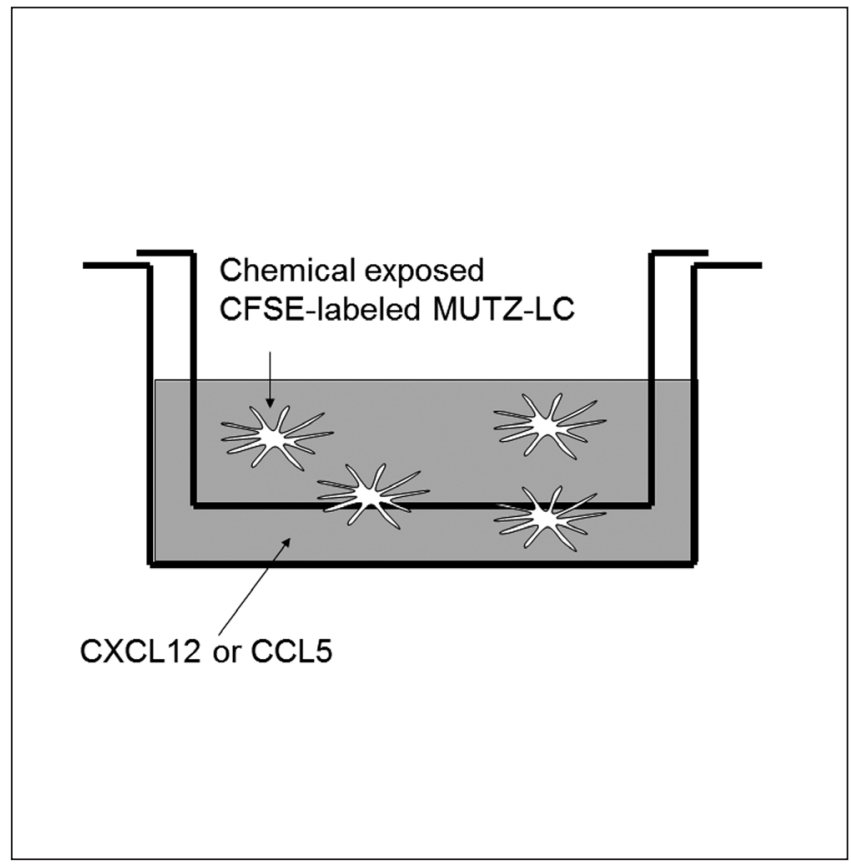

Fig. 8: Dendritic cell based migration assay to predict potential sensitizers

MUTZ-LC cells are labeled with a fluorescent carboxyfluorescein succinimidyl ester (CFSE)-tag and placed in a $5 \mu \mathrm{m}$ pore-size transwell insert and allowed to migrate towards the lower well after contact with a sensitizer. The fluorescence intensity of the lower chamber is measured with the aid of a Victor ${ }^{2}$ Wallac multicolor plate-reader.

Prior to performing the migration assay, cells are labeled with CFSE (carboxyfluorescein succinimidyl ester), placed in the upper section of a dual chamber test system and exposed to test chemicals for 24 hours (Fig. 8). After 16 hours, migration is assessed by counting MUTZ-LC in the lower chamber where either CXCL12 or CCL5 is placed. The principle of the method is based on evidence that immature MUTZ-LC express the receptors for CCL5 and only low levels of the CXCL12 receptor CXCR4, thus enabling them to migrate preferentially to CCL5 upon exposure to non-sensitizers, whereas maturing MUTZLC downregulate the receptors for CCL5 and upregulate the CXCL12 receptor CXCR4, thus enabling them to migrate preferentially to CXCL12 upon sensitizer exposure. The most discriminating feature, and the basis for the assay, is that both irritants and contact sensitizers induce migration of Langerhans cells from the epidermis to the dermis, but in the case of irritants this migration is CCL5 dependent, while it is CXCL12 dependent in the case of contact sensitizers. The ratio between migration towards CXCL12 or to CCL5 represents an index for distinguishing sensitizers from non-sensitizers, being above one for the former and below one for the latter. This model is very sensitive, considering that MUTZ-3 cells also have good metabolic activity. The main drawbacks are the complexity of the system and the expertise that is required to perform it. 
Supported by the promising results, a ring study was performed with three laboratories and 9 chemicals. The first stage of the project focused on protocol optimization (Rees et al., 2011). In spite of the complexity, the model proved very robust, as all three laboratories returned consistent results.

\section{The T-cell priming assay / T-cell library}

(by Stefan F. Martin)

The most distinctive feature of contact allergens is their antigenicity, i.e., the potential to form T-cell epitopes that induce a chemical specific T-cell response. For this reason, an assay based on the T-cell response may be the most specific tool for the identification of contact allergens. The problem is that Tcell assays generally are quite complex and are based on primary cells.

The hTCPA (human T-cell priming assay) is a multiparametric flow cytometry based assay. The method is based on a coculture system that measures the effect derived from the contact of T-cells with DC cells previously activated and chemically modified by the test substance in a way to serve as antigen presenting cells. Naïve T-cells are isolated from PBMC (peripheral blood mononuclear cells) derived from healthy donors and sorted according to the expression of CD45RA and CCR7 and the lack of CD45RO and CD25. The test is usually repeated on T-cells derived from 5 different donors in order to minimize donor-to-donor variability. Immature DCs (iDC) are activated by LPS and partially by the test substance and are cultured with the T-cells for 9 days. Actually, instead of activating the iDC cells before, the test substance can be added directly to the co-culture system or after binding with a protein. As a followup step of the assay, T-cells are isolated again and re-stimulated with autologous DC and the same control chemicals to assess antigen-specificity (Martin et al., 2010; Dietz et al., 2010; Richter et al., 2012). Comparison of the proliferation during stimulation and re-stimulation is an important parameter. The second, more reliable and robust readout is the expression of IFN- $\gamma$, as it has been demonstrated that this cytokine is efficiently produced by T-cells in response to contact allergens. This parameter shows more effective results when TNF- $\alpha$ is measured simultaneously, since some donors fail to respond by IFN- $\gamma$ production. Readouts of other exogenous cytokines are included in the assay in order to enhance in vitro detection of T-cells that are specifically primed by test chemicals.

Preliminary results demonstrated the capability of this assay to effectively predict antigenicity of chemicals, including drugs. Cosmetics Europe is now funding a project aimed at the optimization and harmonization of the Sens-it-iv (Dietz et al., 2010; Richter et al., 2012) and Lyon protocol (Vocanson et al., 2008) and its extension to predict sensitization potency using frequency and T-cell receptor repertoire analysis. The opportunity to apply the T-cell amplification method may go beyond the testing of sensitizers, making it the possible to predict immunogenicity, to assess immunocompetence, to monitor response to vaccination, and eventually to generate T-cells for cellular immunotherapy (Geiger et al., 2009). This assay may be very helpful in the identification of weak allergens.

\section{The genomic GARD assay for prediction of sensitizers} (by Carl Borrebaeck)

The GARD assay (Genomic Allergen Rapid Detection) is a novel genomic assay based on a predictive biomarker signature for sensitization. The objective was to develop a simple predictive in vitro assay with a high throughput format that allows for reduced cost and assay time while maintaining high sensitivity and specificity. The aim was also to correlate pathway activation to chemical potency. This assay utilizes the key deterministic role of DCs in the sensitization phase and is based on the DC-like human cell line MUTZ-3. Cells are stimulated for 24 hours with chemicals in non-toxic concentrations (>90\% relative viability), after which the RNA is collected. GARD was developed using 38 reference chemicals of known sensitization potency: 18 non-sensitizers and 20 sensitizers, including extreme, strong, moderate, and weak representatives. A gene signature of 200 biomarkers, called the GARD signature, was identified by analyzing data from genomewide transcriptomics of the groups of sensitizers versus nonsensitizers and vehicle controls. The bioinformatics analysis included statistical analysis with refinement by backward elimination and aided by PCA analysis (principal component analysis). The identity of the transcripts and their involvement in intracellular signaling pathways confirmed the biological relevance of the prediction signature (Johansson et al., 2011). In the assay, the gene expression induced by the novel tested chemicals with unknown sensitizing ability will be compared to the profile of the GARD gene signature. Every tested chemical will be given a positive or negative decision value as the readout of their sensitizing capacity. The overall accuracy of GARD for a blinded test was $90 \%$. As a further development, the assay is now also being evaluated for respiratory sensitizing compounds, with very promising results.

\section{Immunomodulatory properties of inhaled \\ chemicals (by Armin Braun)}

The irritation and the sensitization derived through respiratory contact is another very serious hazard that must be considered when assessing chemical substances. At the moment, in vivo animal models do not fit the regulatory purpose for the assessment of respiratory sensitization. For this reason, there is an urgent need for a human-based model for predicting lung inflammation and allergy. With this purpose, the ex vivo technology of PCLS (precision cut lung slices) was applied to human tissue and evaluated to determine whether it could represent a valid model for sensitization. The first step was the development of valid culture conditions to retain full viability and functionality of the tissue (Sens-it-iv newsletter no 14 , January 2008). Ad hoc experiments using the immune modulator lipopolysaccharide could demonstrate that PCLS are a functional 3D organ culture system, as the response is valid for at least 24 hours with the expression of MHC class II, resulting in increased levels of TNF- $\alpha$, RANTES, IL- $1 \alpha$ and other specific chemokines. Moreover, the immune response could be suppressed by the addition of drugs, for example, 
dexamethasone. The resulting inflammatory response is highly comparable to the in vivo situation as it is observed for patients after inhalation of LPS (Switalla et al., 2010).

This model was challenged with the Sens-it-iv set of chemicals (Tab. 1): PCLS expression of, for example, TNF- $\alpha$ and IL-1 $\alpha$ was significantly different when known respiratory sensitizers, contact sensitizers, and non-sensitizers were tested at sub-toxic doses.

Further research is focused on finding other biomarkers that also may represent sensitization effects. The model is currently pre-validated in three German laboratories.

\section{In vitro models for respiratory sensitizers}

(by Erwin Roggen)

In vitro assessment of respiratory sensitizers has not yet reached the same level as in vitro assessment of skin sensitizers. The main reason for this is the cellular (about 60 different cell types) and structural complexity of the respiratory tract, stretching from the nose down to the alveolar space in the lungs. In addition, the lack of a qualified human data set, as well as of a trustworthy in vivo animal model, makes it difficult to establish a set of compounds useful for test development and evaluation.

Two systems were identified as potential breakthroughs. Both systems allow both acute and chronic exposure to chemicals that are directly settled over the surface, even without the need to prepare a chemical solution. This is very important, as most of the respiratory sensitizers are not stable in water and thus in culture medium.

One significant breakthrough in the development of an in vitro alveolar model was published by Hermanns and co-workers (2009). It is based on a co-culture of the human bronchial cell line H441 and the human microvascular endothelial cell line, ISO-HAS-1. The endothelial cell line was found to be important for the establishment of an epithelial barrier with a transepithelial electrical resistance (TEER) that was comparable with the generally accepted in vivo TEER in human lungs. The system was shown to have in vivo like functionality in terms of morphology and responses to well-known immune modulators. The alveolar-endothelial model was challenged with non-toxic levels of chemicals, either from the luminal or from the basolateral side of the barrier. The impact of the test compounds on the cells was investigated using a multiplex array for measuring the cytokine release in both upper and lower compartments of the assay wells. Skin sensitizers were characterized by an upregulation on the luminal side of CD54 and CCL-1, in combination with a downregulation of CXCL1, IL- $1 \alpha$ and RANTES on the basolateral side. Interestingly, the specific profile for respiratory sensitizers seems to point to the opposite direction, with downregulation in the luminal compartment and an upregulation in the basolateral compartment. Hexachloroplatinate has a different response suggesting that the mechanism for metals is different.

A second significant breakthrough was provided by the MucilAir model from Epithelix ${ }^{\circledR}$, which is based upon primary human bronchial cells. This system has many advantages, as it reproduces all main functions, including the appearance of cili- ated, mucus, and basal cells, the establishment of absorption/ secretion properties, and the stabilization of electrophysiological properties. Typical readouts of the experiments are TEER, cell viability, and changes in the expression levels of a panel of cytokines that discriminated in a set of pilot studies respiratory sensitizers from skin sensitizers and irritants. The model proved to be very reproducible when the chemicals were applied at nontoxic concentrations.

Further investigation is ongoing in order to understand the capability of the model to give correct outcomes when applied to an extended set of compounds, including proteins. Simultaneously, other commercially available bronchial models will be evaluated and compared with the MucilAir model.

\subsection{Validation and regulatory procedures}

Chair: H. J. Thierse

\section{The ECVAM validation process \\ (by Alexandre Angers)}

Test methods that are meant for regulatory use must undergo a rigorous scientific evaluation. Validation is defined as the process by which the reliability and relevance of a test is established for a specific purpose (OECD, 2005). Reliability is the extent of reproducibility of results within and between laboratories and over time, while relevance is the relationship between the test and the effect in the target species. The validation process aims to characterize the usefulness of the test method for a specific purpose and its limitations.

In the European Union, the validation process is the core activity of the European Union Reference Laboratory for Alternatives to Animal Testing (EURL-ECVAM). Prospective and retrospective validation studies are conducted in order to fulfill the information requirements according to the modules of the modular approach to validation (Hartung et al., 2004):

- Module 1: Test definition that must embrace the definition of the scientific/regulatory purpose of the test, a description of the mechanistic basis of the test and an optimized protocol (including a prediction model);

- Module 2: Within-laboratory reproducibility that must address the reproducibility over time and for different operators but using the same laboratory set-up;

- Module 3: Transferability in terms of the ability of a test procedure to be accurately and reliably performed in independent, competent laboratories by demonstrating the robustness of a test and the amount of training that will be necessary to successfully transfer the test to a naïve laboratory;

- Module 4: Between laboratory transferability, i.e., a measure of the extent to which different qualified laboratories, using the same protocol and testing the same substances, can produce qualitatively and quantitatively similar results;

- Module 5: The predictive capacity of a test is assessed from the performance of the prediction model (ability to predict the in vivo endpoint) and is influenced by the number and range of test substances selected and the quality of the in vivo data; 
- Module 6: Applicability Domain that is a description of the physicochemical or other properties of the substances for which a test method is applicable for use.

Once these information requirements are fulfilled, the test method undergoes a peer review process before it is considered for regulatory acceptance. The ECVAM Scientific Advisory Committee (ESAC) provides EURL ECVAM with high quality scientific and independent advice on the scientific/technical validity of methods.

With the aim to promote international acceptance of validated alternative methods, EURL ECVAM is partnering with the International Cooperation on Alternative Test Methods (ICATM), which joins efforts from the EU, the USA, Japan, Korea, and Canada. To foster interaction with regulators and stakeholders, EURL ECVAM has set up two consultation networks:

1. The ECVAM Stakeholder Forum (ESTAF) brings together EURL ECVAM's non-governmental stakeholders (e.g., industry associations, civil society/non-governmental organizations, and research foundations and organizations) in order to strengthen participatory approaches supporting communication and cooperation.

2. The network with the Member State single points of contact for preliminary assessment of regulatory relevance (PARERE) provides advice on the regulatory relevance and suitability of alternative approaches proposed for validation in order to improve the process of method development from the beginning of the validation process to the adoption of the method for regulatory purposes.

Usually, the validation process involves a pre-validation phase. Pre-validation is conducted to optimize the protocol, generate preliminary information on the within- and betweenlaboratory reproducibility, as performed on a small number of chemicals, and provide initial evidence on the test method's predictive capacity.

\section{Pre-validation of a tiered approach (by Marc Teunis)}

The validation of a tiered approach is not very common, as the general approach is the assessment of one method at a time. Within Sens-it-iv, two interesting methods were developed: the NCTC-assay (Corsini et al., 2009) identifying skin sensitizers and the EE model providing information about the potency class of the test chemical. The principle of the tiered approach is very simple: a chemical is tested with the first assay and, only if it is positive, i.e., it is a sensitizer, it is tested in the second assay for measuring the potency.

The pre-validation phase was initiated with the collaboration of 6 laboratories (2 developers and 4 naïve laboratories). The exercise included evaluation of transferability and optimization of the protocol. In particular, the dose finding step seemed to be the most critical. The chemical selection was from a list of 68 chemicals with known classification and potency. Coded chemicals were distributed to the labs, including information only on solubility.

The study was finalized and the results were analyzed by a statistician. The results currently are being discussed by the prevalidation management group and will be published soon.

\subsection{Scientific spin-offs and premature tests}

Chair: E. Roggen

Innate immune mechanisms in contact

allergy (by Stefan F. Martin)

Innate immune mechanisms in contact allergy still need thorough investigation to determine all the mechanisms that are involved in an allergic reaction. Recent studies have shown clearly that contact allergens have autoadjuvant effects that lead to the efficient activation of the innate immune system, provoking skin inflammation, even in germ-free mice (Martin et al., 2011; Martin, 2012; Kaplan et al., 2012). In addition, they form T-cell epitopes that lead to ACD. Actually, most of the contact allergens have this dual activity, which depends on their protein reactivity. It has been demonstrated in the CHS model that TLR2 and TLR4 are necessarily involved in the allergic reaction to trinitrochlorobenzene (TNCB), dinitrochlorobenzene (DNCB) and oxazolone. Other in vivo experiments provided evidence that the induction of reactive oxygen species (ROS) and the degradation of the extracellular matrix component hyaluronic acid represent key steps in the process (Esser et al., 2012). When skin cells are stressed by contact allergens, they start releasing ATP, which triggers a series of reactions that end in the activation of the NLRP3 inflammasome and transformation of pro-IL-1 $\beta$ to IL- $1 \beta$ and pro-IL-18 to IL- 18 . Blocking one of those interconnected pathways interrupts the sensitization process and, in some cases, also prevents elicitation of CHS in successfully sensitized mice. This may result in the development of causative treatments for patients with ACD (Martin et al., 2011; Martin, 2012).

Some irritants amplify contact dermatitis. This is not generic, i.e., different irritants have a different effect. Moreover, the result from a formulation may be different. If there are, for example, three weak contact allergens in a final product or weak contact allergens plus an irritant substance, a threshold may be overcome that allows for successful sensitization by the allergenic mixture (Martin, 2012).

\section{Crucial role for human Toll-like receptor 4 in the development} of contact allergy to nickel (by Matthias Goebeler)

From an early stage of in vivo research, it became evident that both the adaptive and the innate immune system are required for the development of contact allergy. In particular, pattern recognition receptors of the innate immune system, such as Toll-like receptors (TLRs), appeared to be directly activated by specific contact allergens (Schmidt et al., 2010a; Schmidt and Goebeler, 2011).

As one of the major causes of contact allergies in the EU, impairing the lives of about 45 million citizens, the contact allergen nickel and the chemically closely related hapten cobalt were investigated. Both were found to bind directly to TLR4 resulting in receptor dimerization (Raghavan et al., 2012) and subsequent triggering of pro-inflammatory responses by activating NF-KB and p38 MAP kinase (Viemann et al., 2007). This mechanism was demonstrated to be species-specific. In fact, nickel and cobalt activated human but not murine TLR4; there- 


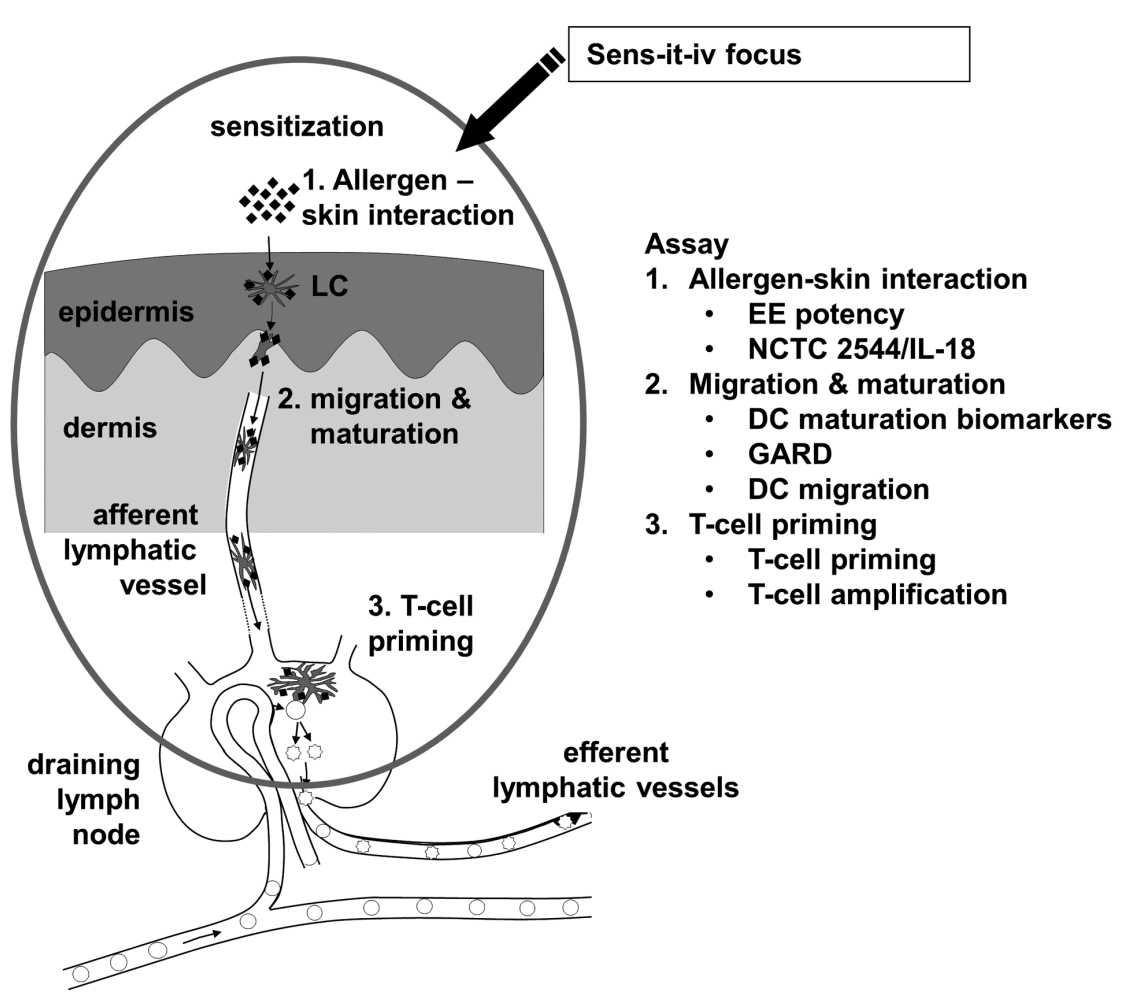

Fig. 9: Skin equivalent model for combining most relevant Sens-it-iv assays

fore, studying these processes in animal models or animal cell lines may not be suitable for prediction of the allergic potential of new compounds in humans. Furthermore, nickel promotes apoptosis of keratinocytes that occurred as a consequence of the downregulation of the anti-apoptotic protein c-FLIP (Schmidt et al., 2010b). Epidermal spongiosis, a histological hallmark of contact dermatitis, is a consequence of apoptosis and obviously is triggered by the metal hapten.

\section{NK/NKT and Th17/Th22 cells in allergy}

\section{(by Andrea Cavani)}

Skin biopsies and peripheral blood from a sensitized patient were investigated to unravel the principle of the allergic reaction (Pennino et al., 2010). From this analysis, it was demonstrated that the intensity of ACD reactions depends on the cytotoxic potential of infiltrating T-cells, targeting hapten-loaded keratinocytes, and resulting in spongiosis and microvesiculation. In addition, keratinocytes activated by T-cell-derived mediators release a plethora of cytokines and chemokines, which promote the accumulation of leukocytes and modulate the inflammatory response. A major role is played by IL-17, which strongly affects the innate immune function of human keratinocytes.

The infiltrate in the skin also comprises myeloid and plasmacytoid dendritic cells, as well as NK cells and NK-T-cells. Details of this process were elucidated by Pennino et al. (2010), who demonstrated that NK cells, although being extremely po- tent in killing transformed or viral-infected autologous cells, do not induce apoptosis of hapten-coupled keratinocytes. However, once activated by infiltrating Th1 and Th17 lymphocytes, they become potent effector cells in the pathogenesis of ACD by releasing pro-inflammatory cytokines and by induction of keratinocyte apoptosis. Although in this scenario NK cells appear to act as a T-cell-dependent magnification tool for ACD expression, it could not be excluded that NK lymphocytes play a role in an earlier phase of the immune reaction, as a consequence of T-cell independent activation pathways.

Although NK cells represent only $10 \%$ of the infiltrating lymphocytes and are outnumbered by IFN- $\gamma$-producing T-cells, their contribution to the maintenance of a Th1-dominated microenvironment could be relevant. In fact, whereas only a fraction of infiltrating lymphocytes is specific for the causative hapten, NK cells uniformly release IFN- $\gamma$ when exposed to T-cell-derived cytokines, IL-2 in particular (Carbone et al., 2010).

In conclusion, our data reinforce the notion that full expression of allergic contact dermatitis requires a coordinated interaction between adaptive and innate immune mechanisms.

\section{An immunocompetent skin equivalent model \\ (by Sue Gibbs)}

The ideal future will have an immunocompetent equivalent model that may replace one-to-one the in vivo method with the construction of a functional, immunocompetent, full thickness skin equivalent model (Ouwehand et al., 2011). 
The idea is to put together many separate methods that have been developed already within the Sens-it-iv project (Fig. 9). The skin equivalent model is already available, but it is implemented with MUTZ-3 derived DC and LC. The full human-derived epidermal equivalent provides the physical barrier function and simulates the correct bioavailability of the substance that is topically applied over the skin surface. The metabolic activity must be preserved, and the dermal compartment must have fibroblasts available to initiate the DC migration. MUTZ-3 progenitors are used since they can be differentiated into both MUTZ-3 DC and MUTZ-3 LC. Electron microscopy shows Birbeck granules within immature MUTZ-3 LC.

Comparison with control skin is impressive from many points of view, even though the most relevant data is the response with non-toxic concentrations of Nickel sulphate and resorcinol. Beyond the regular expression of typical biomarkers, such as CD83 and IL-1 $\beta$, the most relevant result is the migration of MUTZ-LC from epidermis to the fibroblast-populated dermal compartment, with a dose dependent effect. The model still has some limitations, including the complexity of the system. So far, it has been challenged with only few substances, but it represents a unique research tool to study LC biology under controlled in vitro conditions.

\section{Pro-hapten signals in THP-1 cells}

(by Emanuela Corsini)

Most false negative results obtained with regular tests derive from pre/pro-haptens, i.e., chemicals that become sensitizers after being either metabolized or chemically modified by atmospheric agents.

In this context, we previously demonstrated in the human promyelocytic cell line THP-1 that all allergens tested, with the exception of the prohapten isoeugenol, induced a dose-related release of IL-8 (Mitjans et al., 2008, 2010). However, we also observed that the well-known pre/pro-haptens cinnamyl alcohol, iso-eugenol, and eugenol, while failing to induce IL-8 release, induced a dose dependent expression of IL-8 mRNA and MAPK p38 activation after 3 hours of exposure. MAPK p38 activation or IL-8 mRNA expression may thus offer the possibility of quickly identifying all allergens, including pre and pro-haptens.

The mechanism was further investigated by assessing whether this abnormal behavior was regulated by the AU-rich element binding proteins HuR and tristetraprolin (TTP) or by the downstream molecule suppressor of cytokine signaling (SOCS)-3 (Galbiati et al., 2012). Time course experiments of IL-8 mRNA expression and assessment of IL-8 mRNA half-life indicated a decreased IL-8 mRNA stability in isoeugenol-treated cells. We could demonstrate that a combination and regulation of HuR and TTP following exposure to contact allergens resulted in a different modulation of IL-8 mRNA half-life and release. SOCS family proteins form part of a classical negative feedback system that regulates cytokine signal transduction (Skazik et al., 2011). In our experimental conditions, SOCS3 was induced only in isoeugenol treated cells. Its modulation, however, did not rescue the lack of IL- 8 release, indicating that it is unlikely to be involved in the lack of IL- 8 production.
These results show that TTP, a negative regulator of the expression and stability of several genes, was induced by moderate allergens and influenced the rate at which mRNA was degraded and translated into protein (Blackshear, 2002). It is tempting to speculate that this different behavior also may occur in vivo, and may contribute to our understanding of allergen potency.

\section{Conclusions}

The work done during the 5-year Sens-it-iv project was intensive and effective. Many methods have entered the pre-validation process, and several others, though less advanced, generated interesting contributions to the molecular understanding of sensitization mechanisms. There are also promising strategies to distinguish between skin and respiratory sensitizers. The possibility of evaluating the potency of chemical sensitizers with in vitro methods will probably become reality in the near future.

The real question is whether we are now ready to substitute the in vivo methods, i.e., the LLNA, which is considered the gold standard in the evaluation of skin sensitizers. Considering the in vitro methods that are now available, it may be possible to define whether a chemical is or is not a sensitizer, even though the full validation process is not over, and therefore it is still not possible to define the level of confidence of that result. Models that are already available are probably enough for hazard assessment. More efforts should be addressed to refine existing methods and to further develop new methods that lead to an improved awareness of the real mechanisms of a chemical in triggering a sensitization reaction in exposed humans. A unique strategy cannot be defined, and it must be built case by case, depending on the physical chemical properties of the substance, existing information, and last but not least, the details and knowledge that are required for the sensitization definition.

\section{References}

Aeby, P., Ashikaga, T., Bessou-Touya, S., et al. (2010). Identifying and characterizing chemical skin sensitizers without animal testing: Colipa's research and method development program. Toxicol In Vitro 24, 1465-1473.

Akiba, H., Kehren, J., Ducluzeau, M. T., et al. (2002). Skin inflammation during contact hypersensitivity is mediated by early recruitment of $\mathrm{CD}^{+} \mathrm{TC} 1$ cells inducing keratinocyte apoptosis. J Immunol 168, 3079-3087.

Antonopoulos, C., Cumberbatch, M., Mee, J. B., et al. (2008). IL-18 is a key proximal mediator of contact hypersensitivity and allergen-induced Langerhans cell migration in murine epidermis. J Leukoc Biol 83, 361-367.

Ashikaga, T., Yoshida, Y., Hirota, M., et al. (2006). Development of an in vitro skin sensitization test using human cell lines: the human Cell Line Activation Test (h-CLAT). I. Optimization of the h-CLAT protocol. Toxicol In Vitro 20, 767-773.

Ashikaga, T., Sakaguchi, H., Okamoto, K., et al. (2008). Assessment of the human cell line activation test (h-CLAT) for 
skin sensitization; Result of the first Japanase inter-laboratory study. AATEX 13, 27-35.

Ashikaga, T., Sakaguchi, H., Sono, S., et al. (2010). A comparative evaluation of in vitro skin sensitisation tests: the human Cell-line Activation Test (h-CLAT) versus the Local Lymph Node Assay (LLNA). ATLA 38, 275-284.

Baron, J. M., Holler, D., Schiffer, R., et al. (2001). Expression of multiple cytochrome p450 enzymes and multidrug resistanceassociated transport proteins in human skin keratinocytes. $J$ Invest Dermatol 116, 541-548.

Bergstrom, M. A., Ott, H., Carlsson, A., et al. (2007). A skin-like Cytochrome P450 cocktail activates pro-haptens to contact allergenic metabolites. J Invest Dermatol 127, 1145-1153.

Blackshear, P. J. (2002). Tristetraprolin and other CCCH tandem zinc-finger proteins in the regulation of mRNA turnover. Biochem Soc Trans 30, 945-952.

Carbone, T., Nasorri, F., Pennino, D., et al. (2010). Clinical immunology $\mathrm{CD} 6^{\text {high }} \mathrm{CD} 16-\mathrm{CD} 62 \mathrm{~L}-\mathrm{NK}$ cells accumulate in allergic contact dermatitis and contribute to the expression of allergic responses. J Immunol 184, 1102-1110.

Casati, S., Aeby, P., Kimber, I., et al. (2009). Selection of chemicals for the development and evaluation of in vitro methods for skin sensitisation test. ATLA 37, 305-312.

Corsini, E., Mitjans, M., Galbiati, V., et al. (2009). Use of IL-18 production in a human keratinocyte cell line to discriminate contact sensitizers from irritants and low molecular weight respiratory allergens. Toxicol In Vitro 23, 789-796.

Cumberbatch, M., Dearman, R. J., Antopoulos, C., et al. (2001). Interleukin-18 induces Langerhans cell migration by a tumor necrosis factor- $\alpha$ and IL- $1 \beta$-dependent mechanism. Immunology 102, 323-330.

Daneshian, M., Leist, M., and Hartung, T. (2010). The Center for Alternatives to Animal Testing - Europe (CAAT-EU): a transatlantic bridge for the paradigm shift in toxicology. ALTEX 27, 63-69.

Dietz, L., Bosque, A., Pankert, P., et al. (2009). Quantitative DY-maleimide-based proteomic 2-DE labelling strategies using human skin proteins. Proteomics 9, 4298-4308.

Dietz, L., Esser, P. R., Schmucker, S. S., et al. (2010). Tracking human contact allergens: From mass spectrometric identification of peptide-bound reactive small chemicals to chemicalspecific naive human t-cell priming. Toxicol Sci 117, 336347.

Dietz, L., Kinzebach, S., Ohnesorge, S., et al. (2012). Proteomic allergen-peptide/protein interaction assay for the identification of human skin sensitizers. Toxicol In Vitro, Epub ahead of print. http://dx.doi.org/10.1016/j.tiv.2012.08.013

Dos Santos, G. G., Spiekstra, S. W., Sampat-Sardjoepersad, S. C., et al. (2011). A potential in vitro epidermal equivalent assay to determine sensitizer potency. Toxicol In Vitro 25, 347357.

Esser, P. R., Wölfle, U., Dürr, C., et al. (2012). Contact sensitizers induce skin inflammation via ROS and hyaluronic acid degradation in humans and mice. PLoS One 7, e41340.

Fleischel, O., Giménez-Arnau, E., and Lepoittevin, J. P. (2009). Nuclear magnetic resonance studies on the covalent modification of amino acids thiol and amino residues by monofunc- tional aryl 13C-isocyanates, models of skin and respiratory sensitizers. Transformation of thiocarbamates into urea adducts. Chem Res Toxicol 22, 1106-1115.

Galbiati, V., Mitjans, M., Lucchi, L., et al. (2011). Further development of the NCTC 2544 IL-18 assay to identify in vitro contact allergens. Toxicol In Vitro 25, 724-732.

Galbiati, V., Carne, A., Mitjans, M., et al. (2012). Isoeugenol destabilizes IL-8 mRNA expression in THP-1 cells through induction of the negative regulator of mRNA stability tristetraprolin. Arch Toxicol 86, 239-248.

Geiger, R., Duhen, D., Lanzavecchia, A., and Sallusto, F. (2009). Human naive and memory $\mathrm{CD} 4^{+} \mathrm{T}$-cell repertoires specific for naturally processed antigens analyzed using libraries of amplified T-cells. J Exp Med 206, 1525-1534.

Gerberick, G. F., Vassallo, J., Bailey, R., et al. (2004). Development of peptide reactivity assay for screening contact allergens. Toxicol Sci 81, 332-343.

Gerberick, F., Vassallo, J., Foertsch, L., et al. (2007a). Quantification of chemical peptide reactivity for screening contact allergens. Toxicol Sci 97, 417-427.

Gerberick, F., Vassallo, J., Foertsch, L., et al. (2007b). Quantification of Chemical peptide reactivity for screening contact allergens: A classification tree model approach. Toxicol Sci 97, 417-427.

Gerberick, F., Troutman, J., Foertsch, L., et al. (2009). Investigation of peptide reactivity of pro-hapten skin sensitizers using a peroxidase-peroxide oxidation system. Toxicol Sci 112, 164-174.

Goebel, C., Aeby, P., Ade, N., et al. (2012). Guiding principles for the implementation of non-animal safety assessment approaches for cosmetics: skin sensitisation. Regul Toxicol Pharmacol 63, 40-52.

Hagvall, L., Baron, J. M., Börje, A., et al. (2008). Cytochrome $\mathrm{P} 450$-mediated activation of the fragrance compound geraniol forms potent contact allergens. Toxicol Appl Pharmacol 233, 308-313.

Hartung, T., Bremer, S., Casati, S., et al. (2004). A modular approach to the ECVAM principles on test validity. ATLA 32, 467-472.

Heiss, K., Junkes, C., Guerreiro, N., et al. (2005). Subproteomic analysis of metal-interacting proteins in human B cells. Proteomics 5, 3614-3622.

Hennino, A., Vocanson, M., Toussaint, Y., et al. (2007). CD8+ T cells initiate atopic dermatitis lesions. J Immunol 178, 55715577.

Hermanns, M. I., Fuchs, S., Wenzelm, K., et al. (2009). A primary human coculture model of the alveolo-capillary unit to study mechanisms of injury to the peripheral lung. Cell Tissue Res 336, 91-105.

Hooyberghs, J., Schoeters, E., Lambrechts, N., et al. (2008). A cell-based in vitro alternative to identify skin sensitizers by gene expression. Toxicol Appl Pharmacol 231, 103-111.

Jaworska, J., Harol, A., Kern, P. S., and Gerberick, G. F. (2011). Integrating non-animal test information into an adaptive testing strategy - skin sensitization proof of concept case. ALTEX 28, 211-225.

Johansson, H., Lindstedt, M., Albrekt, A. S., and Borrebaeck, C. 
(2011). A genomic biomarker signature can predict skin sensitizers using a cell-based in vitro alternative to animal tests. BMC Genomics 12,399.

Kaplan, D. H., Igyártó, B. Z., and Gaspari, A. A. (2012). Early immune events in the induction of allergic contact dermatitis. Nat Rev Immunol 12, 114-124.

Kehren, J., Desvignes, C., Krasteva, M., et al. (1999). Cytotoxicity is mandatory for $\mathrm{CD}^{+} \mathrm{T}$ cell-mediated contact hypersensitivity. J Exp Med 189, 779-786.

Kimber, I., Agius, R., Basketter, D. A., et al. (2007). Chemical respiratory allergy: opportunities for hazard identification and characterisation. ATLA 35, 243-265.

Krasteva, M., Kehren, J., Sayag, M., et al. (1999). Contact dermatitis II. Clinical aspects and diagnosis. Eur J Dermatol 9, 144-159.

Lambrechts, N., Vanheel, H., Nelissen, I., et al . (2010a). Assessment of chemical skin sensitizing potency by an in vitro assay based on human dendritic cells. Toxicol Sci 116, 122-129.

Lambrechts, N., Vanheel, H., Hooyberghs, J., et al. (2010b). Gene markers in dendritic cells unravel pieces of the skin sensitization puzzle. Toxicology Letters 196, 95-103.

Lambrechts, N., Nelissen, I., Van Tendeloo, V., et al. (2011). Functionality and specificity of gene markers for skin sensitization in dendritic cells. Toxicology Letters 203, 106-110.

Landsteiner, K. and Jacobs, J. (1936). Studies on the sensitization of animals with simple chemical compounds. $J$ Exp Med 64, 625-639.

Martin, S. F., Esser, P. R., Schmucker, S., et al. (2010). T-cell recognition of chemicals, protein allergens and drugs: towards the development of in vitro assays. Cell Mol Life Science 67, 4171-4184.

Martin, S. F., Esser, P. R., Weber, F. C., et al. (2011). Mechanisms of chemical-induced innate immunity in allergic contact dermatitis. Allergy 66, 1152-1163.

Martin, S. F. (2012). Contact dermatitis: from pathomechanisms to immunotoxicology. Exp Dermatol 21, 382-389.

Maxwell, G., Aeby, P., Ashikaga, T., et al. (2011). Skin sensitisation: The Colipa strategy for developing and evaluating non-animal test methods for risk assessment. ALTEX 28, 5055.

Megherbi, R., Kiorpelidou, E., Foster, B., et al. (2009). Role of protein haptenation in triggering maturation events in the dendritic cell surrogate cell line THP-1. Toxicol Appl Pharmacol 238, 120-132.

Mitjans M., Viviani B., Lucchi L., et al. (2008). Role of p38 MAPK in the selective release of IL- 8 induced by chemical allergen in naive THp-1 cells. Toxicol In Vitro 22, 386-395.

Mitjans, M., Galbiati, V., Lucchi, L., et al. (2010). Use of IL-8 release and p38 MAPK activation in THP-1 cells to identify allergens and to assess their potency in vitro. Toxicol In Vitro 24, 1803-1809.

NRC (2007). Toxicity Testing in the Twenty-first Century: A Vision and A Strategy. Washington DC, USA: National Academies Press. http://www.nap.edu/catalog.php?record_ id $=11970$

Nukada, Y., Ashikaga, T., Miyazawa, M., et al. (2012). Prediction of skin sensitization potency of chemicals by human Cell
Line Activation Test (h-CLAT) and an attempt at classifying skin sensitization potency. Toxicol In Vitro 26, 1150-1160.

OECD (2005). Test Guideline 34. Guidance document on the validation and international acceptance of new or updated test methods for hazard assessment. http://www.oecd. org/officialdocuments/displaydocumentpdf?cote=env/jm/ mono(2005)14\&doclanguage $=$ en (accessed on $17^{\text {th }}$ June 2012).

Okamura, H., Tsutsui, H., Komatsu, T., et al. (1995). Cloning of a new cytokine that induces IFN- $\gamma$ production by T-cells. Nature 378, 88-91.

Ott, H., Wiederholt, T., Bergström, A. M., et al. (2010). Highresolution transcriptional profiling of chemical-stimulated dendritic cells identifies immunogenic contact allergens, but not pro-haptens. Skin Pharmacol Physiol 23, 213-224.

Ouwehand, K., Santegoets, S. J., Bruynzeel, D. P., et al. (2008). CXCL12 is essential for migration of activated Langerhans cells from epidermis to dermis. European J Immunol 38, 3050-3059.

Ouwehand, K., Scheper, R. J., de Gruijl, T. D., and Gibbs, S. (2010). Epidermis-to-dermis migration of immature Langerhans cells upon topical irritant exposure is dependent on CCL2 and CCL5. European J Immunol 40, 2026-2034.

Ouwehand, K., Spiekstra, S. W., Waaijman, T., et al. (2011). Technical advance: Langerhans cells derived from a human cell line in a full-thickness skin-equivalent undergo allergeninduced maturation and migration. J Leukoc Biol 90, 10271033.

Pennino, P., Eyerich, K., Scarponi, C., et al. (2010). Cellular immunology and immune regulation IL-17 amplifies human contact hypersensitivity by licensing hapten nonspecific Th1 cells to kill autologous keratinocytes. J Immunol 184, 48804888.

Raghavan, B., Martin, S. F., Esser, P. R., et al. (2012). Metal allergens nickel and cobalt facilitate human Toll-like receptor 4 homodimerisation independently of MD2. EMBO Reports 13, 1109-1115.

Rees, B., Spiekstra, S. W., Carfi, M., et al. (2011). Inter-laboratory study of the in vitro DC migration assay for identification of contact allergens. Toxicol In Vitro 25, 2124-2134.

Reuter, H., Spieker, J., Gerlach, S., et al. (2011). In vitro detection of contact allergens: Development of an optimized protocol using human peripheral blood monocyte-derived dendritic cells. Toxicol In Vitro 25, 315-323.

Richter, A., Schmucker, S., Esser, P. R., et al. (2012). Human T-cell priming assay (hTCPA) for the identification of contact allergens based on naive T-cells and DC - IFN- $\gamma$ and TNF- $\alpha$ readout. Toxicol In Vitro, Epub ahead of print. doi: 10.1016/j. tiv.2012.08.007

Rovida, C., Basketter, D., Casati, S., et al. (2007). Management of an integrated project (Sens-it-iv) to develop in vitro tests to assess sensitisation. ATLA 35, 317-322.

Sakaguchi, H., Ashikaga, T., Miyazawa, M., et al. (2006). Development of an in vitro skin sensitization test using human cell lines; human Cell Line Activation Test (h-CLAT). II. An inter-laboratory study of the h-CLAT. Toxicol In Vitro 20, 774-784. 
Sakaguchi, H., Ryan, C., Ovigne, J. M., et al. (2010). Predicting skin sensitization potential and inter-laboratory reproducibility of a human Cell Line Activation Test (h-CLAT) in the European Cosmetics Association (COLIPA) ring trials. Toxicol In Vitro 24, 1810-1820.

Schmidt, M., Raghavan, B., Müller, V., et al. (2010a). A crucial role for human Toll-like receptor 4 in the development of contact allergy to nickel. Nature Immunol 11, 814-819.

Schmidt, M., Hupe, M., Endres, N., et al. (2010b). The contact allergen nickel sensitizes primary human endothelial cells and keratinocytes to TRAIL-mediated apoptosis. J Cell Mol Med 14, 1760-1776.

Schmidt, M. and Goebeler, M. (2011). Nickel allergies: Paying the Toll for innate immunity. J Mol Med (Berl) 89, 961-970.

Schoeters, E., Verheyen, G. R., Nelissen, I., et al. (2007). Microarray analyses in dendritic cells reveal potential biomarkers for chemical-induced skin sensitization. Mol Immunol 44, 3222-3233.

Skazik, C., Heise, R., Ott, H., et al. (2011). Active transport of contact allergens in human monocyte-derived dendritic cells is mediated by multidrug resistance related proteins. Arch Biochem Biophys 508, 212-216.

Spiekstra, S. W., Dos Santos, G. G., Scheper, R. J., and Gibbs, S. (2009). Potential method to determine irritant potency in vitro - Comparison of two reconstructed epidermal culture models with different barrier competency. Toxicol In Vitro 23, 349-355.

Switalla, S., Lauenstein, L., Prenzler, F., et al. (2010). Natural innate cytokine response to immunomodulators and adjuvants in human precision-cut lung slices. Toxicol Appl Pharmacol 246, 107-115.

Teunis, M., Corsini, E., Smits, M., et al. (2012). Transfer of a twotiered keratinocyte assay: IL-18 production by NCTC2544 to determine the skin sensitizing capacity and epidermal equivalent assay to determine sensitizer potency. Toxicol In Vitro, Epub ahead of print.

Thierse, H. J., Moulon, C., Allespach, Y., et al. (2004). Metalprotein complex-mediated transport and delivery of $\mathrm{Ni}^{2+}$ to TCR/MHC contact sites in nickel-specific human $\mathrm{T}$ cell activation. J Immunol 172, 1926-2119.

Thierse, H. J., Helm, S., Pink, M., and Weltzien, H. U. (2007). Novel fluorescence assay for tracking molecular and cellular allergen-protein interactions. J Immunol Methods 328, 1420.

Troutman, J. A., Foertsch, L. M., Kern, P. S., et al. (2011). The incorporation of lysine into the peroxidase peptide reactivity assay for skin sensitization assessments. Toxicol Sci 122, 422-436.
Viemann, D., Schmidt, M., Tenbrock, K., et al. (2007). The contact allergen nickel triggers a unique inflammatory and proangiogenic gene expression pattern via independent activation of NF-KB and HIF-1 $\alpha . J$ Immunol 178, 3198-3207.

Vocanson, M., Saint-Mezard, P., Cluzel-Tailhardat, M., et al. (2006). CD8 ${ }^{+} \mathrm{T}$ cells are effector cells of contact dermatitis to common skin allergens in mice. J Invest Dermatol 126 , 815-820.

Vocanson, M., Cluzel-Tailhardat, M., Poyet, G., et al. (2008). Depletion of human peripheral blood lymphocytes in $\mathrm{CD} 25^{+}$ cells allows for the sensitive in vitro screening of contact allergens. J Invest Dermatol 128, 2119-2122.

Vocanson, M., Hennino, A., Rozières, A., et al. (2009). Effectors and regulatory mechanisms in allergic contact dermatitis. Allergy 64, 1699-1714.

Vocanson, M., Hennino, A., Rozieres, A., et al. (2010). Inducible costimulator (ICOS) is a marker for highly suppressive antigen-specific $\mathrm{T}$ cells sharing features of Th17/Th1 and regulatory T cells. J Allergy Clin Immunol 126, 280-289.

\section{Acknowledgements}

The authors warmly thank all the other speakers of this final workshop: P. Aeby, A. S. Albrekt, A. Angers, T. Ashikaga, J. Baron, C. Borrebaeck, A. Braun, P. Budde, A. Cavani, E. Corsini, S. Gibbs, M. Goebeler, A. Groenewoud, J. Hooyberghs, P. Kern, I. Kimber, J. P. Lepoittevin, M. Lindstedt, I. Nelissen, J. F. Nicolas, K. Park, H. Reuter, H. Sakaguchi, S. Teissier, and H. J. Thierse.

Special acknowledgement goes to H. Hermanns who passionately followed the Sens-it-iv project from the very beginning and retired just at the end of it, and to all other scientists who contributed to making this fantastic project a reality but who could not participate in this final congress: M. Assenmacher, S. Casati, P. Esser, M. Fairley, D. Fernández, C. Helma, C. Krul, J. McLeod, E. Maggi, H. Merk, D. Naisbitt, I. Pike, V. Rogiers, and F. Sallusto, plus the members of the advisory committee, D. Basketter, I. Kimber, H. Van Loveren, M. Pallardy, and D. Warheit.

\section{Correspondence to}

Costanza Rovida

CAAT-Europe at the University of Konstanz

Universitätsstr. 10

78464 Konstanz

Germany

e-mail: costanza.rovida@chimici.it 